\title{
The impact of public information on bidding in highway procurement auctions
}

\author{
Dakshina G. De Silva ${ }^{\mathrm{a}}$, Timothy Dunne ${ }^{\mathrm{b}}$, \\ Anuruddha Kankanamge ${ }^{\mathrm{d}}$, Georgia Kosmopoulou ${ }^{\mathrm{c}, *}$ \\ ${ }^{\mathrm{a}}$ Texas Tech University, USA \\ ${ }^{\mathrm{b}}$ Federal Reserve Bank of Cleveland, USA \\ ${ }^{\mathrm{c}}$ University of Oklahoma, USA \\ ${ }^{\mathrm{d}}$ University of Peradeniya, Sri Lanka
}

Received 25 July 2006; accepted 11 July 2007

Available online 26 July 2007

\begin{abstract}
A number of papers in the theoretical auction literature show that the release of information regarding the seller's valuation of an item can cause bidders to bid more aggressively. This widely accepted result in auction theory remains largely untested in the empirical literature. Recent theoretical work has also shown that this effect can be more pronounced in auctions with larger common cost uncertainty. We examine the impact of a policy change by the Oklahoma Department of Transportation that led to the release of the state's internal estimate of the costs to complete highway construction projects. We perform a differences-in-differences analysis comparing bidding in Texas, a state that had a uniform policy of revealing the same information all throughout the period of analysis, to bidding in Oklahoma. Our results show that, in comparison to Texas auctions, the average bid in Oklahoma fell after the change in engineers' cost estimate (ECE) policy. This decline in bids was even larger for projects where the common uncertainty in costs is greater. Moreover, the within-auction standard deviation of bids fell after the change in ECE policy with the most significant decline observed again in projects with greater common cost uncertainty.
\end{abstract}

(C) 2007 Elsevier B.V. All rights reserved.

JEL classifications: D44; H57

Keywords: Information release; Procurement auctions

\footnotetext{
${ }^{*}$ Corresponding author. Tel.: + 14053253083 ; fax: + 14053255842.

E-mail address: georgiak@ou.edu (G. Kosmopoulou).
} 


\section{Introduction}

A fundamental result from auction theory is that the public release of information regarding the valuation of an object can lead to more aggressive bidding behavior (see Milgrom and Weber, 1982; Harstad, 1990; Campbell and Levin, 2000). In a competitive environment, the release of information can intensify competition among bidders by making values more predictable. This effect is pronounced in auctions of objects with common value uncertainty (Goeree and Offerman, 2003). Public information can also lower the relative value of a bidder's own private information thus reducing his rents. These predictions are widely accepted but remain largely untested using field auction data. For the most part, the empirical evidence on the impact of public information dissemination is confined to laboratory experiments (see Kagel et al., 1987., 1995; Goeree and Offerman, 2002). ${ }^{1}$

This study examines the role of information release on bidding behavior using data from highway construction procurement auctions. Each state in the US conducts transportation procurement auctions and billions of dollars of construction projects are awarded annually through this process. The auctions are first-price sealed bid auctions and are held in each state at regular intervals throughout the year. While the auction format is quite similar in most states, a feature that varies across states is the information provided to bidders regarding the state's internal estimate of the cost of a project. ${ }^{2}$ Some states release this information prior to bidding and others do not. Oklahoma recently changed its policy in this regard. Prior to the change in policy, it was illegal for state officials to disclose the state's cost estimate before bids were opened. During a 6-month period beginning at the end of 1999, the Oklahoma Legislature initiated a set of changes to state laws that overturned this policy. Bidders now have access to the state's cost estimate prior to bid submission. This change in Oklahoma's information policy is similar, in spirit, to the information release discussed in Milgrom and Weber (1982) and this information policy change forms the basis of our test of the theory.

As mentioned above, the existing evidence on the effect of public information release in auctions is quite limited and is mostly coming from experiments. The empirical literature's closest evidence is of simulations of a public information disclosure. In a study of open auctions of apartments in Sweden, Eklof and Lunander (2003) estimate the distribution of private values when the reserve prices are secret. They then simulate the effect of moving to an open reserve price mechanism and find that the seller's revenue would be about $10 \%$ higher if the reserve price was announced. The empirical studies of drainage auctions examine how asymmetries in the precision of the bidders' information affect their bidding behavior (see Hendricks and Porter, 1988; Hendricks et al., 1994). The focus is generally placed on studying the magnitude of information rents in asymmetric environments when

\footnotetext{
${ }^{1}$ The results from experiments performed in Kagel et al. (1987) and Goeree and Offerman (2002) agree with the predictions of Milgrom and Weber (1982). Alternatively, Kagel et al. (1995) show that in some experiments when the bidders' behavior is out of the equilibrium path such policy prescriptions fail.

${ }^{2}$ This is called the engineers' cost estimate and is used as a benchmark to judge the submitted bids. For example, in Oklahoma, the state uses the engineers' cost estimate to establish a reserve value for a project and if the low bid is $7 \%$ above the engineers' cost estimate, the state may reject the low bid and re-auction the project off at a later time.
} 
one bidder can acquire better information than others (see Hendricks et al., 1987; Porter, 1995). ${ }^{3}$ In wildcat auctions where information is relatively symmetric, there is some evidence that royalty schemes that provide revenue insurance increase bids. In Treasury bill auctions, Nyborg et al. (2002) show that increased market volatility can lead to lower demand, lower prices and increased dispersion of bids. Part of this behavior is due to risk aversion. In a study of computer auctions on Ebay, Yin (2006) examines the effect of value dispersion and seller reputation on prices. She finds that the seller's reputation complements information provided by the auction site by lending more credibility to it. However, none of these empirical papers provides a direct test of Milgrom and Weber's result that the provision of public information regarding the valuation of an item affects bidding behavior. The predictions of this theory remain largely untested using a natural experiment and field auction data.

To this end, we empirically examine the impact of the release of public information in Oklahoma auctions using a differences-in-differences approach and compare the changes in bidding behavior in auctions held in Oklahoma and Texas. Texas had a uniform information release policy throughout the entire period and we use the Texas auctions as a control group. The data include over 13,000 submitted bids by construction firms in Oklahoma and Texas over the period 1998-2003. Our empirical analysis provides evidence in support of the theory; the average level of bids is lower after the release of additional information. Despite the competitive pressure created by the information release, the lower average bids do not result in statistically significant lower winning bids.

The theory suggests that the effects of information release should be more apparent in auctions with a greater degree of common cost uncertainty. Within the set of auctions used in this analysis, we isolate two types of projects that appear to differ significantly in the level of common cost uncertainty associated with the specific construction tasks. The two project types are asphalt-paving projects and bridge construction/repair work. We argue that in asphalt projects one has to rely more on the individual firm's state of equipment and internal efficiency to determine the cost, while in bridge work projects there is more uncertainty that is common to all bidders. ${ }^{4}$ We find, in agreement with the theory, that the effect of information release is stronger for bridge work projects. To our knowledge, this is the first paper that studies and compares the impact of a public information release among auctions with different degrees of common cost uncertainty.

The remainder of the paper is organized as follows. Section 2 describes the theoretical framework and the bidding process. Section 3 provides a description of the data while Sections 4 and 5 report the results. In Section 6, we offer some concluding comments.

\footnotetext{
${ }^{3}$ Athey and Levin (2001) provide another example of an asymmetric environment in timber auctions. They show how bidders strategically use their private information in bidding. A recent theoretical study by Mares and Harstad (2003) relates the two strands of literature by examining the benefits of private information disclosure to a subset of bidders and compares those to the benefits of public disclosure of information.

${ }^{4} \mathrm{We}$ discuss below the differences in the uncertainty of costs associated with asphalt and bridge work. In short, asphalt paving projects are relatively straightforward as the job descriptions typically specify an area of roadwork to be surfaced, a depth of surfacing required, and the material to be used in the surfacing project. In bridge work, there is more uncertainty. Soil conditions at a site may not be fully known until excavation work begins and repairs may not be fully understood until some demolition work is undertaken.
} 


\section{Information policy and auctions}

\subsection{Information release and auction theory}

In first-price sealed bid auctions with affiliated values, Milgrom and Weber (1982) have shown that the release of public information induces more competitive bidding and may result in higher revenues. In Theorem 16, they state that "In a first price auction a policy of publicly revealing the seller's information cannot lower and may raise the expected price." 5 In such an environment, the winner of an auction is the one that has the most optimistic estimate relative to his competitors. A failure to foresee this fact and take it into account when formulating the bidding strategies leads to the winner's curse. In a competitive environment, the release of information can have two effects on bidding behavior. First, it can make values more predictable thus alleviating the winner's curse effect and encouraging more intense competition from all bidders. Second, it can reduce the impact of the bidder's own private information on his estimate of the value and, as a result, reduce his information rents.

To formalize the role of public information in auctions, we present a simple model of competitive bidding with additive and separable common and private cost components. This model, first introduced by Goeree and Offerman (2003), provides useful directions for the empirical analysis that follows. The framework produces a simple bidding function with the added advantage that it allows us to assess the relative magnitude of the impact of an information release when the size of the common cost component relative to the private cost component changes. We can also provide an explanation for the observed difference in the impact that the release of information has on projects with predominantly private costs (such as asphalt), and projects with predominantly common costs (such as bridge work). Finally, due to its simplicity, the framework can predict effects on the variance of bids.

There are $n \geqslant 2$ risk neutral bidders who compete for a government contract in a first price sealed bid auction. The cost of the contract to a bidder, $i$, consists of two components: The private cost component $c_{i}$ and the common cost component $V$. Each one of the $n$ bidders has an unbiased estimate, $v_{i}$, of the true common cost. The common cost component is modeled here as the average of the bidders' estimates, i.e., $V=\sum_{V=1}^{n} v_{i} / n{ }^{6}$ The private and common cost estimates are identically and independently distributed across bidders. The density of the private $\operatorname{cost} c_{i}$ to bidder $i$ is $\mathrm{f}_{c}$ that is strictly positive on the support $\left[c_{L}, c_{H}\right]$. Similarly, the density of the common cost component is $\mathrm{f}_{v}$ and it is strictly positive on its support $\left[v_{L}, v_{H}\right]$. We assume that the densities $\mathrm{f}_{c}$ and $\mathrm{f}_{v}$ are logconcave. ${ }^{7}$

In this environment, a bidder who is awarded a contract at a bid of $b_{i}$ receives a net profit of $b_{i}-c_{i}-V$. The following strategy is the unique symmetric equilibrium bidding

\footnotetext{
${ }^{5}$ See also Theorem 5.4.18 in Milgrom (2004).

${ }^{6}$ This modeling framework has been previously used in many theoretical papers such as Albers and Harstad (1991), Bikhchandani and Riley (1991), Vincent (1995), Klemperer (1998), Bulow et al. (1999), and Goeree and Offerman (2003). Alternatively, in the more traditional formulation adopted by Wilson (1969), bidders draw their signals from a known distribution conditional on the realization of $V$. These two formulations have the same qualitative features (see also the discussion in Goeree and Offerman, 2003; Milgrom, 2004).

${ }^{7}$ The assumption of logconcavity is discussed in detail in Goeree and Offerman (2003). It guarantees that a lower privately observed cost implies, on average, a lower overall cost thus ensuring monotonicity and existence.
} 
strategy for bidder $i$ who faces $n-1$ rivals in the first price auction:

$$
B_{n-1}\left(s_{i}\right)=\frac{n-1}{n} E_{n-1}\left[v \mid s \geqslant s_{i}\right]+E_{n-1}\left[y_{1} \mid y_{1} \geqslant s_{i}\right],
$$

where $s_{i}=v_{i} / n+c_{i}$ is $i$ 's privately observed component of the cost and $y_{1}$ is the lowest value of the remaining $n-1$ estimates of $s$. This function is derived in Appendix A. An alternative way to express this bidding function for any estimate $x$ of the privately observed component of the cost is

$$
B_{n-1}(x)=E_{n-1}\left[V+c \mid s_{i}=x, Y_{1}=x\right]+E_{n-1}\left[y_{1}-Y_{1} \mid s_{i}=x, Y_{1}=x\right],
$$

where $Y_{1}$ is the lowest estimate of $s$ among all bidders. The first term of this expression represents the bidder's estimate of the expected value of the total cost, and the second term is the potential information rent of the bidder. As a result, each bid is an estimate of the entire cost increased by the private information rent.

The seller can also obtain an estimate of the common cost $V$. If he decides to obtain and release that estimate to the bidders, the value of $n$ increases by one and the weight placed upon any privately observed signal becomes lower, $s_{i}=v_{i} /(n+1)+c_{i}$. As a result, the private information rents are reduced and bidders bid relatively more aggressively. The larger the relative size of the common cost component, the more aggressive the bidding behavior is expected to be after the information is released. If the seller's estimate carried a larger weight than any other estimate, his decision to acquire and release it to bidders would reduce the private information rents even more leading to lower bids on average. With the release of that information all bidders get to learn the state's estimated value of the common cost. ${ }^{8}$ Bids become more concentrated as the information rents are reduced at every level of bid.

The above analysis assumes the number of bidders is known. Even if the number of bidders is unknown, the qualitative effect of the policy change on the equilibrium bidding strategy will be the same as in the model with a known number of bidders. The release of information will induce more aggressive bidding behavior on average.

As a demonstration, consider a procurement auction in which the number of rivals is unknown when bids are submitted. Assume a symmetric environment, i.e., every bidder holds the same beliefs about the number of rivals he faces. Under the information structure assumed here and according to Proposition 4 in Goeree and Offerman (2003), there is revenue equivalence among the standard auction formats. According to Krishna (2002, p. 36), in such an environment the equilibrium bid function when there is bidder uncertainty is a weighted average of the equilibrium bids when the number of bidders is known to all. As a result, the bidding strategy is going to be

$$
\begin{aligned}
B(x)= & \sum_{n=1}^{N} \frac{p_{n-1}\left[1-F_{s}(x)\right]^{n-1}}{\sum_{n=1}^{N} P_{n-1}\left[1-F_{s}(x)\right]^{n-1}} B_{n-1}(x), \\
= & \sum_{n=1}^{N} \frac{p_{n-1}\left[1-F_{s}(x)\right]^{n-1}}{\sum_{n=1}^{N} P_{n-1}\left[1-F_{s}(x)\right]^{n-1}} \\
& \times\left[E_{n-1}\left[V+c \mid s_{i}=x, Y_{1}=x\right]+E_{n-1}\left[y_{1}-Y_{1} \mid s_{i}=x, Y_{1}=x\right]\right],
\end{aligned}
$$

\footnotetext{
${ }^{8}$ Indeed, according to a discussion with a state official the engineering estimate obtained by the state is not unveiling the true common cost but is rather another estimate that involves some amount of uncertainty as well. This is a feature that we were hoping to capture in our modeling effort.
} 
Table 1

State policies on ECE information release

\begin{tabular}{ll}
\hline ECE policy & State \\
\hline No release before the bid letting-ECE release after & AK, AZ, CO, DE, GA, ID, IN, KY, ME, MN, \\
& NM, OH, SC, TN, WV \\
AR, IL, IA, KS, MD, NE, VT, VA \\
No release before or after the bid letting & AL, NJ, MO, WI \\
Release of a range of values before-no release after & CT, HI, MS, MT, NY, ND, OR, WA, WY, PA \\
Release of a range of values before-ECE release after & CA, FL, SD, NC \\
Release of a budgeted estimate before-ECE release after & RI \\
Release of a budgeted estimate before-no ECE release after & LA, MA, MI, NV, OK, TX, UT, NH \\
ECE release before &
\end{tabular}

where $F_{s}$ is the distribution of the combined signal, $\left[1-F_{s}(x)\right]^{n-1}$ is the probability that the lowest of $n-1$ values of the combined signal $s$ is greater than $x, \sum_{n=1}^{N} P_{n-1}\left[1-F_{s}(x)\right]^{n-1}$ is the overall probability that a bidder will win the auction if he bids $B_{n-1}(x)$ and $p_{n-1}$ is the probability that any participating bidder assigns to the event that he faces $n-1$ other bidders. ${ }^{9}$ Comparing this with expression (2) it is evident that the qualitative effects of the policy change will be similar.

\subsection{Oklahoma ECE policy change}

As mentioned in the introduction, before November 1999, the law in Oklahoma explicitly prohibited the release of the state's engineers' cost estimate (ECE) prior to bid letting. In fact, very few people within the department of transportation (DOT) were entrusted with this information and it was a felony offense to release the estimate. In November 1999, the law was changed. The Oklahoma statute (OS 61, Section 116) was amended to include the phrase "The public agency's engineering estimate of the actual cost of the project shall not be considered confidential and shall be open for public inspection." Bidders could now request access to the ECE prior to bid letting. In April 2000, the legislature amended the section further to state that the ECE "shall be available to the public in accordance to the Oklahoma Open Records Act." This change allowed the full release of the details of the ECE to all potential bidders.

Table 1 shows the current ECE release policy for individual states. Only eight states release the actual estimates, either with their advertisement of the projects or upon request. Five states provide a total "budgeted" amount that may include costs that are not part of the bid amount. Fourteen states release a range of possible costs instead of the actual estimate. Twenty-three states do not release the engineering estimate before the bid letting. Of those, eight do not release it even after the bids are opened.

\footnotetext{
${ }^{9}$ Assume that the potential bidders enter the auction with a probability $q$. Let $q$ be exogenous for the moment implying an exogenous entry decision. The probability $p_{n-1}$ will then be

$$
p_{n-1}=\left(\begin{array}{c}
N-1 \\
n-1
\end{array}\right) q^{n-1}[1-q]^{N-n} .
$$

Later in the paper we endogenize the entry decision.
} 
Oklahoma is not the only state that has enacted changes in ECE policy. There have been recent shifts in ECE policy in Florida, New Hampshire, North Carolina, Utah and Illinois. Prior to these recent changes, Florida and New Hampshire did not provide any estimates of the ECE before or after bid letting, and North Carolina and Utah released the ECE only after bids were opened. Currently, New Hampshire and Utah release the ECE prior to bidding (as in Oklahoma) and Florida and North Carolina provide a budgeted amount that is based on the ECE prior to bid letting. Alternatively, Illinois changed its policy in the opposite direction, restricting access to the ECE, and state authorities in Michigan are also considering a similar policy change.

\subsection{Empirical tests}

Overall, the theory predicts the release of information is likely to induce aggressive bidding behavior. The larger the common value component of the cost, the lower the bids and the lower the variance of bids is expected to be after the information is released. On the other hand, if the costs were purely private, in a competitive environment, the release of information would have no effect on the bids. Our empirical analysis will perform three main tests of this theory. First, we will estimate the overall effect of the change in ECE policy on bids and winning bids. Second, we will estimate the effects of the change in ECE policy on projects with differing levels of common and private cost components. We expect that the change in ECE policy will more greatly affect bidding in project types with larger common cost components. Third, we model the variance of bids as a function of the change in policy. We expect variances to decline after the change in ECE policy.

\section{Data and measurement issues}

This study employs data obtained from the Oklahoma (ODOT) and Texas (TXDOT) Departments of Transportation on auctions of construction projects for the period between January 1998 and August 2003. ${ }^{10}$ The data include auctions from the entire state of Oklahoma and from the North Texas and Panhandle construction districts in Texas. These areas of Texas border on Oklahoma, have similar topography and soil conditions, and use similar grades of construction materials as those in Oklahoma. ${ }^{11}$ For each project auctioned off, we know the contractors that purchased plans (plan holders), the bids submitted by each contractor if they bid, the winning bidder, and the winning bid. Any contractor wishing to bid on a project must purchase a plan from the state and thus the list of plan holders describes the potential competition in an auction. The plan holder list is public information available to all bidders prior to the auction letting. In addition, both states provide data describing each project. The data give the location, a detailed description of the tasks, the estimated time to completion and, most importantly, the ECE for each project. With this information, we construct a panel data set where an observation in our data set represents a plan held and possibly a bid submitted by a firm for a given

\footnotetext{
${ }^{10}$ The Oklahoma dataset is obtained from three reports in the ODOT website, namely the as read bid report, the low bid report, and the award notice. The Texas data are provided by the TXDOT. We use the 1997 data to initialize variables on bidding history and capacity utilization that are discussed more fully below.

${ }^{11}$ We use all well-defined project types (i.e., asphalt, concrete, bridge, traffic signal, grade and drainage/grading projects) in both states but exclude miscellaneous projects. Miscellaneous projects are typically smaller projects that may involve such tasks as mowing, painting, sign replacement, and construction at rest stops.
} 
Table 2

Auction summary statistics for Oklahoma and Texas

\begin{tabular}{|c|c|c|c|}
\hline Variable & $\begin{array}{l}\text { Before November } \\
1999\end{array}$ & $\begin{array}{l}\text { From November } \\
1999 \text { to March } 2000\end{array}$ & After March 2000 \\
\hline \multicolumn{4}{|c|}{ (a) Summary statistics for Oklahoma auctions } \\
\hline Total number of auctions & 698 & 143 & 1220 \\
\hline Number of awarded projects & 620 & 116 & 1072 \\
\hline Average number of plan holders & $5.536(3.010)$ & $6.308(3.499)$ & $6.257(3.590)$ \\
\hline Average number of bidders & $3.132(1.565)$ & $3.300(1.754)$ & $3.475(1.786)$ \\
\hline Relative value of bids & $1.117(.363)$ & $1.112(.277)$ & $1.027(.295)$ \\
\hline Relative value of winning bids & $.968(.200)$ & $.961(.171)$ & $.906(.197)$ \\
\hline
\end{tabular}

(b) Summary statistics for Texas Districts that border Oklahoma auctions

\begin{tabular}{llll} 
Total number of auctions & 527 & 108 & 913 \\
Number of awarded projects & 506 & 104 & 891 \\
Average number of plan holders & $6.167(3.907)$ & $6.824(3.289)$ & $7.404(3.486)$ \\
Average number of bidders & $3.613(1.654)$ & $4.157(1.958)$ & $4.588(2.207)$ \\
Relative value of bids & $1.105(.240)$ & $1.071(.229)$ & $1.051(.248)$ \\
Relative value of winning bids & $1.011(.179)$ & $.986(.205)$ & $.942(.183)$ \\
\hline
\end{tabular}

(c) Summary statistics for Oklahoma repeated auctions

$\begin{array}{llll}\text { Total number of auctions } & 53 & 27 & 60 \\ \text { Number of awarded projects } & 27 & 20 & 41 \\ \text { Average number of plan holders } & 4.943(2.274) & 5.407(2.576) & 5.383(2.630) \\ \text { Average number of bidders } & 2.830(1.236) & 3.259(1.933) & 2.683(1.049) \\ \text { Relative value of bids } & 1.195(.324) & 1.138(.175) & 1.168(.382) \\ \text { Relative value of winning bids } & .934(.094) & 1.011(.072) & 1.028(.248)\end{array}$

Standard deviations are in parentheses.

project. Bidders may place multiple individual bids in a month or may elect not to bid at all in some months; hence, the panel structure is quite unbalanced.

The top two panels of Table 2 provide a summary of the auction data for Texas and Oklahoma broken out by the ECE policy information periods described above-January 1998-October 1999, November 1999-March 2000, and April 2000-August 2003. The table includes statistics on the number of auctions, bidders, and values of bids submitted. The information on bids is presented as the relative bid which is measured as the bid divided by the engineering cost estimate. ${ }^{12}$ This allows for a direct comparison of bids across projects of different sizes. Three points are worth noting. First, the sample is relatively balanced between Oklahoma and Texas with slightly fewer auctions in Texas compared to Oklahoma in each of the three periods. Second, participation levels, both in terms of the number of plan holders and the number of bidders, are generally higher in Texas compared with Oklahoma. On average, the number of bidders in Texas exceeds that in Oklahoma by .5-1.0 bidders per auction. Third, it appears that, in both Oklahoma and Texas, relative

\footnotetext{
${ }^{12}$ Bajari and Ye (2003) also analyze highway procurement auctions focusing on the relative bids as their measure of bids in an auction. Alternatively, some studies use the log of the bids in their analysis. We estimate our models both ways but report the relative bid results. With regard to ECE policy variables, the relative bid and log of the bids models give qualitatively similar results across our different specifications.
} 


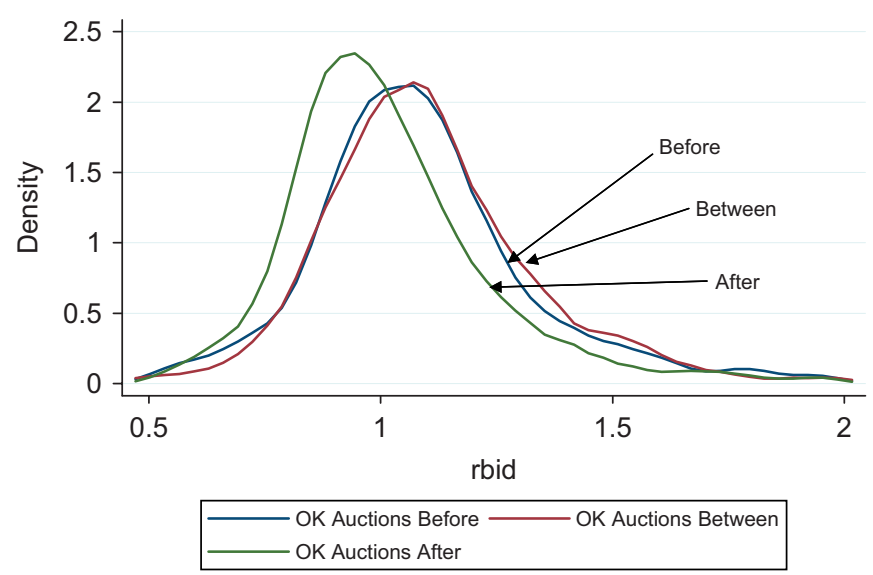

Fig. 1. Kernel density plot of relative bids on all project types for Oklahoma before November 1999, from November 1999 to March 2000, and after March 2000.

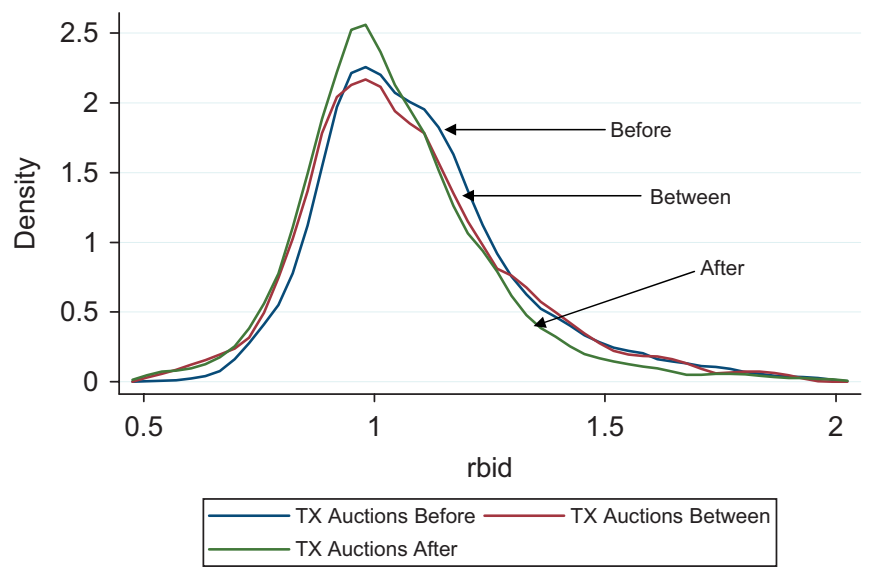

Fig. 2. Kernel density plot of relative bids on all project types for Texas Districts that Border Oklahoma before November 1999, from November 1999 to March 2000, and after March 2000.

bids and relative winning bids have declined over time but the decline is more marked in Oklahoma. This last point is reflected in Figs. 1 and 2. Fig. 1 presents the kernel density plots for the relative bid distributions for the three ECE periods for Oklahoma, and Fig. 2 shows the same set of distributions for Texas. In Oklahoma, the leftward shift of the distribution is considerably more pronounced.

\section{Empirical model and results}

Our first test of the effect of the change in information release policy in Oklahoma will take a panel-data differences-in-differences approach. ${ }^{13}$ We will compare the changes in

\footnotetext{
${ }^{13}$ Clearly, a large number of recent papers in the empirical auction literature have estimated structural models. While a structural approach may allow for the analysis of the effect of a change in information policy on bidder's
} 
bidding behavior in Oklahoma and Texas. In Texas, there was no change in policy with the ECE being available to bidders prior to bid letting for the entire sample. In Oklahoma, there was a distinct change in the policy as described above. We will model this change in information by classifying our auctions into three distinct time periods - pre-November 1999, November 1999-March 2000, and post-March 2000. In the first period, the ECE for Oklahoma projects is not known prior to the bid letting. The second time interval is a period of transition and encompasses the two changes in legislation that occurred in November 1999 and March 2000. In the final time period, the ECE is available to bidders and both legislative changes have been enacted. We will estimate a differences-indifferences model that allows for differential effects across the three time periods. Our basic econometric specification is given below as

$$
y_{\text {iast }}=\alpha_{i}+\beta_{1} D_{s}+\beta_{2} T_{t}+\beta_{3}\left(D_{s} \times T_{t}\right)+\beta_{4} A_{t}+\beta_{5}\left(D_{s} \times A_{t}\right)+x_{\text {iast }}^{\prime} \gamma+\varepsilon_{\text {iast }},
$$

where the unit of observation is firm $i$ bidding in auction $a$ in state $s$ in time period $t$. The dependent variable is the relative bid defined above and the $\beta$ 's measure the change in bidding that occurs between Texas and Oklahoma across the three ECE policy periods. The variable $D_{s}$ takes the value of 1 if the bid was observed in Oklahoma. $T_{t}$ takes the value of 1 for bids observed in the transition period and $A_{t}$ takes the value of 1 in the period after the information release. The coefficient on $D_{s}, \beta_{1}$, measures the average difference in bidding between Oklahoma and Texas auctions. The coefficients, $\beta_{2}$ and $\beta_{4}$, capture the average difference in bidding in auctions during the transition period and after the ECE policy change period, respectively. $\beta_{3}$ measures the difference in bidding that occurs in Oklahoma auctions compared to Texas auctions during the transition period and $\beta_{5}$ measures the difference in bidding that occurs in Oklahoma auctions compared to Texas auctions in the period after the ECE policy change. Our main interest is on the coefficient $\beta_{5}$, expressed in this DID model by

$$
\begin{aligned}
& {\left[E\left[y \mid x, D_{s}, A_{t}=1\right]-E\left[y \mid x, D_{s}=1, A_{t}, T_{t}=0\right]\right]} \\
& \quad-\left[E\left[y \mid x, D_{s}=0, A_{t}=1\right]-E\left[y \mid x, D_{s}, A_{t}, T_{t}=0\right]\right]
\end{aligned}
$$

where the first two terms $\left(E\left[y \mid x, D_{s}, A_{t}=1\right]-E\left[y \mid x, D_{s}=1, A_{t}, T_{t}=0\right)\right.$ represent the difference in the expected value of bids in the period after the information release for both states together and in Oklahoma separately. The last two terms $\left(E\left[y \mid x, D_{s}=0\right.\right.$, $\left.\left.A_{t}=1\right]-E\left[y \mid x, D_{s}, A_{t}, T_{t}=0\right]\right)$ isolate the expected difference in bids after the information release period for both states. If the theory is applicable to these data, we expect that $\beta_{5}$ should be negative. $\beta_{3}$ is more difficult to make predictions about since the ECE policy changes are not fully enacted until the end of the time period. In fact, the actual policies are in flux until the passage of the Opens Record Act provision. A crucial requirement is that we control for any additional factors that could differentially impact Oklahoma auctions compared to Texas auctions in the later periods in order to interpret $\beta_{5}$ as reflecting the

(footnote continued)

profit by estimating the underlying distribution of costs, the differences-in-differences approach offers a number of advantages, as well. It is a straightforward way to model our policy change without making strong assumptions regarding the structure of the auctions. It provides flexibility in the estimation allowing controls for bidder heterogeneity, auction characteristics and rival characteristics. It also allows for a wide range of robustness checks. 
change in ECE information policy. All models will include bidder fixed effects $\left(\alpha_{i}{ }^{\prime} s\right)$ as well as a set of controls ( $x_{\text {iast }}$ 's) for bidder, rival, auction, and business conditions variables. ${ }^{14}$

\subsection{Variable definitions}

The dependent variable used throughout the analysis is the relative bid. The independent variables can be classified into five main groups-ECE information policy controls, auction characteristics, bidder characteristics, rival characteristics and business environment characteristics. Table B1 in Appendix B provides a detailed definition for each of the variables used in the study. There are two auction-level variables - the number of bidders and a set of project-type dummies. The number of bidders controls for differences in competition in auctions and the project-type dummies control for the fact that we observe differences in bidding across project categories. We include two bidder characteristic variables, in addition to firm-fixed effects, that measure the cost heterogeneity of biddersthe bidder's capacity utilization rate and the bidder's distance to a project. As a bidder's capacity utilization rises or as a bidder's distance to a project increases, we expect a bidder to submit higher bids. Three variables that measure rival characteristics are also constructed. First, we utilize past information on rivals' bidding success and construct the average winning percentage of all rival plan holders in an auction. This is a measure of rival toughness. If firms face a set of tough rivals, we expect them to bid more aggressively. Second, we include the rivals' minimum distance to the project and the minimum backlog of the rivals. These variables are also used to control for rival cost heterogeneity and are similar to variables used by Bajari and Ye (2003). ${ }^{15}$

In the analysis that follows, it is important to control for factors that change over time other than the ECE information. Three variables are included that control for the business environment: (1) The monthly variation in the amount of projects being let, (2) the monthly unemployment rate, and (3) the monthly building permits. The first variable measures the real volume of projects auctioned off in each state in each month. The aggregate real volume of projects auctioned off in a month and in a state will vary due to budgetary conditions and seasonal factors. This may affect bidding behavior if firms bid more or less aggressively as the relative real volume of projects being let changes. Summary statistics of all the regression variables are presented in Table B2.

\subsection{Differences-in-differences results}

All the differences-in-differences models are estimated with firm-fixed effects and include a set of monthly dummy variables along with the controls for bidder, rival, business conditions and auction characteristics discussed above. The standard errors reported are cluster-robust standard errors where the clustering is on firms. We estimate the models on

\footnotetext{
${ }^{14}$ Our models are estimated with firm-fixed effects to control for bidder heterogeneity. A related model has been estimated in the literature using auction-fixed effects but that is not possible here because the ECE policy control variables do not vary within auctions. To check how our data compare to other papers that estimate the reduced form bid model with auction fixed effects, we replicated the relative bid model reported in Bajari and Ye (2003). Our results are quite similar in spirit to Bajari and Ye (2003). Relative bids increase with a firm's distance to a project and decline when firms have more prior production experience and when rivals are close to the project. The one difference is that we did not find a statistically significant effect for a firm's capacity utilization on bids.

${ }^{15}$ See also Jofre-Bonet and Pesendorfer (2003) and De Silva et al. (2003, 2005).
} 
Table 3

Panel-fixed effects differences-in-differences estimates

\begin{tabular}{lcc}
\hline Variable & Base model & \\
\cline { 2 - 3 } & Relative bids & Relative winning bids \\
& $(1)$ & $(2)$ \\
\hline Oklahoma bids $\left(\beta_{1}\right)$ & $.002(.066)$ & $-.042(.037)$ \\
Bids from November 1999 to March $2000\left(\beta_{2}\right)$ & $-.034^{* *}(.013)$ & $-.018(.022)$ \\
Oklahoma bids from November 1999 to March $2000\left(\beta_{3}\right)$ & $.038(.024)$ & $.015(.028)$ \\
Bids after March $2000\left(\beta_{4}\right)$ & $-.034^{* *}(.010)$ & $-.031^{* *}(.014)$ \\
Oklahoma bids after March $2000\left(\beta_{5}\right)$ & $-.050^{* *}(.020)$ & $-.014(.015)$ \\
Number of bidders & $-.015^{* *}(.002)$ & $-.025^{* *}(.003)$ \\
Capacity utilized & $.012(.011)$ & $.027^{*}(.015)$ \\
Distance to the project location & $.006(.004)$ & $.003(.002)$ \\
Average rivals winning to plan holder ratio & $-.058(.081)$ & $-.201^{* *}(.066)$ \\
Closest rival's distance to the project location & $.001(.002)$ & $.003(.002)$ \\
Rivals minimum backlog & $-.000(.001)$ & $.000(.001)$ \\
Seasonally unadjusted unemployment rate & $-.012^{* *}(.005)$ & $-.009^{*}(.005)$ \\
Three month average of the real volume of projects & $-.023^{*}(.012)$ & $-.015(.014)$ \\
Three month average of the number of building permits & $.034(.036)$ & $.019(.040)$ \\
\hline Number of observations & 13,282 & .136 \\
Adj- $R^{2}$ & 3222 \\
\hline
\end{tabular}

**Denotes statistical significance at the $5 \%$ level and * denotes statistical significance at the $10 \%$ level. Robust clustered standard errors using firm level-clusters are in parentheses. All regressions include firm-level fixed effects, five project class dummy variables, and 11 monthly dummy variables.

two samples of bids. One sample includes all bids submitted and our results will measure how changes in ECE policy influence overall bidding behavior. A second sample estimates the model using only winning bids and these runs will assess how the change in ECE policy relates to the winning bid. These latter regressions measure more directly the effect of the ECE policy change on Oklahoma's procurement costs.

Table 3 reports the results for our base model. The first column presents the coefficients for the base model using all relative bids and the second column presents the estimates from the sample restricted to the winning relative bids. The first set of coefficients in the table is the policy response controls. The key parameter of interest in this group is $\beta_{5}$ that measures the difference in bidding between Oklahoma and Texas auctions in the period after the ECE policy change (post-March 2000). Two clear patterns emerge. On average, bidding is lower in Oklahoma after the change in ECE policy by about $5.0 \%$. With regard to the winning bids (column (2)), overall there is no statistically significant effect of the change in ECE policy on the observed winning bids. ${ }^{16}$ In the transition period when ECE policies were being changed, there is no difference in bidding between Oklahoma and Texas. The other policy response coefficients indicate there is no overall mean difference in

\footnotetext{
${ }^{16}$ One possible explanation for the weaker effect on winning bids is that the release of information may result in an upward revision of the costs of a project by a bidder that had a very optimistic estimate of the cost of doing a project. If such an effect was present, this would tend to mute the effect of the release of information predicted by the theory. Kagel and Levin (1986) and Goeree and Offerman (2002) find some evidence of such an effect based on experiments.
} 
relative bids or winning relative bids between Oklahoma and Texas $\left(\beta_{1}\right)$ and over time there has been an overall decline in relative and winning bids in both states $\left(\beta_{4}\right)$.

With regard to the other variables in the model, the number of bidders appears to have the most consistent impact. As the number of bidders increases, bidding becomes more aggressive and winning bids fall. Therefore, increased competition results in lower procurement costs for the states. If the winner has a higher capacity utilization rate, bids tend to be higher. The only rival variable that consistently matters is the average rival winning to plan holder ratio. As rivals get tougher, bids generally decline. The variables that measure business conditions show mixed results. As unemployment rises, bidding becomes more aggressive resulting in lower winning bids. This may reflect the fact that the firms non-highway business has weakened and they become more aggressive in bidding on procurement contracts. Alternatively, we expected to see less aggressive bidding as the volume of projects being let increased. This is not the case. Firms appear to bid somewhat more aggressively as the volume of projects increases although, again, there is no effect on the winning bids. The effect of a rise in building permits is not statistically significantly in most of the specifications.

\subsection{Project differences}

The main results in Table 3 show a significant change in the average bidding behavior after the ECE policy change but no statistically significant effect on winning bids. While these findings offer an overall assessment of the impact of the change in ECE policy on bidding behavior in Oklahoma procurement auctions, the sample pools across projects with very different construction components. The theoretical literature in auctions suggests that the ECE information effect should be more pronounced in auctions where there is greater uncertainty about the cost. To examine the potential differences in the effect of ECE policy across projects, we look at two specific project types, asphalt and bridge work, where we think the relative importance of the common value components differ and where we have significant numbers of projects. Based on discussions with state highway and civil engineers, we believe that asphalt projects appear best described by the independent private value framework. Differences in bids submitted are primarily due to differences in private costs and there is less uncertainty in the costs involved. This is because asphalt projects are generally straightforward, requiring a contractor to lay down a certain thickness and type of asphalt across a specific road surface. For these projects, the quantities and types of material defined in the work items are usually well specified.

On the other hand, the costs associated with bridge construction and repair are often more uncertain. Each bridge is different and bridge construction projects will differ in complexity. Moreover, bridge work may require demolition and excavation in order to fully understand the costs of the job. The state construction engineers and civil engineers we spoke with generally thought that some costs associated with bridge work such as demolition and pier construction were more uncertain than the cost components typically observed in asphalt projects. The uncertainties may be due to the difficulties in assessing soil conditions or discerning the exact repairs that must be done to an existing bridge. ${ }^{17}$

\footnotetext{
${ }^{17}$ These uncertainties are reflected in the detailed work items listed in the project description. In bridge work, there are often unique construction tasks listed as "lump sum" items in the construction plans. For example, bridge demolition is usually listed as a "lump sum" cost item with no detailed breakdown of the specific costs of
} 
Table 4

Summary statistics for asphalt and bridge work projects

\begin{tabular}{|c|c|c|c|c|c|c|}
\hline \multirow[t]{2}{*}{ Variable } & \multicolumn{2}{|l|}{ Full sample } & \multicolumn{2}{|c|}{ For Oklahoma } & \multicolumn{2}{|c|}{$\begin{array}{l}\text { For Texas Districts that } \\
\text { border Oklahoma }\end{array}$} \\
\hline & Asphalt & Bridge & Asphalt & Bridge & Asphalt & Bridge \\
\hline $\begin{array}{l}\text { Mean of the relative bids } \\
\text { before November } 1999\end{array}$ & $1.088(.214)$ & $1.152(.384)$ & $1.086(.211)$ & $1.154(.425)$ & $1.090(.217)$ & $1.148(.294)$ \\
\hline $\begin{array}{l}\text { Mean of the relative bids } \\
\text { after March } 2000\end{array}$ & $1.040(.199)$ & $1.061(.342)$ & $1.053(.196)$ & $1.038(.362)$ & $1.033(.201)$ & $1.106(.292)$ \\
\hline
\end{tabular}

Standard deviations are in parentheses.

This classification of projects agrees with the findings of Hong and Shum (2002). Using a model of affiliated values, they find that bridge projects contain both common and private cost components but road-paving contracts have predominantly private costs. We believe this cross-project comparison offers a more robust application of the differences-indifferences approach in this setting. Policy evaluation using differences-in-differences assumes that we have controlled for all other factors that could differentially affect bidding in Texas and Oklahoma in the pre- and post-ECE policy periods. It is possible that there is an omitted variable affecting bidding in Oklahoma or Texas that we have not controlled for that could bias our results. The bridge-asphalt comparison should shed light on this possibility. If we are simply picking up the effect of an omitted variable that resulted in relatively more aggressive bidding in Oklahoma through our ECE policy variable, it should not differentially affect specific project types within states. The bridge-asphalt comparison effectively allows us to exploit within state variation in the data (across project types) to refine our test.

Table 4 shows descriptive statistics for the asphalt and bridge work samples. Looking at the table, several patterns emerge. While all bids fall over time, there is a strong decline in the average relative bids in the bridge work category, especially in Oklahoma. The standard deviation of relative bids is also much higher in bridge work as compared to asphalt projects in both Texas and Oklahoma. Finally, the standard deviation in bridge work declines more sharply across time in Oklahoma compared with Texas. These patterns are certainly consistent with our story that bridge work projects contain more uncertain cost components and that the uncertainty is declining in Oklahoma. ${ }^{18}$

Our test will be to estimate a differences-in-differences model on asphalt and bridge projects separately using the same specification as presented in Table $3 .{ }^{19}$ We expect to see a larger effect of the change in the ECE policy in the bridge project sample as compared to

\footnotetext{
(footnote continued)

demolition. Alternatively, in asphalt projects an estimate of the amount of asphalt (e.g., in tons) to be used in a project will be clearly stated.

${ }^{18}$ Likewise, in an effort to categorize uncertainty in wildcat auctions, Porter (1995) concentrated on the large dispersion of submitted bids. Based on the variance in bids, he concluded that these auctions could be "regarded as common value auctions, where firms are uncertain about deposit sizes, common extraction costs, or future prices."

${ }^{19}$ This is similar to running a differences-in-differences model where the project-type dummy variable is fully interacted with all the variables in the model.
} 
the asphalt sample. Table 5 presents the results for both asphalt and bridge models focusing on the relative bids variable. The asphalt results, in the first two columns, show there is no effect of the change in ECE policy on bids or winning bids for these projects in the post-March 2000 period. There is a substantial rise in bids in the transition period for asphalt projects. For bridge projects, however, the coefficients that measure the change in bidding after the change in ECE policy are negative and large in magnitude. The results in column (3) show the average relative bid fell by about $9.6 \%$ for bridge projects. The winning relative bid also fell by a similar amount though it is statistically significant at only the $10 \%$ level. This differential impact of the information release across these project groups lends some confidence to the interpretation that the estimated differences-indifferences policy dummies are reflecting changes in the information environment. If the ECE policy variables were simply proxying for some other Oklahoma state level effect (e.g., budget issues), we would expect a uniform effect across these project types. This is not the case.

\subsection{Within-auction variation in bids}

The theory also predicts that when the common cost component is important, bids become more aggressive and more concentrated when information is released. This suggests the within-auction variation in relative bids should fall in response to ECE policy changes in auctions with a greater share of common cost components. In order to examine this issue, we estimate an econometric specification where the dependent variable is the within auction standard deviation of relative bids ( $s d b i d)$. The specification is

$$
y_{\text {ast }}=\alpha_{i}+\beta_{1} D_{s}+\beta_{2} T_{t}+\beta_{3}\left(D_{s} \times T_{t}\right)+\beta_{4} A_{t}+\beta_{5}\left(D_{s} \times A_{t}\right)+z_{\text {ast }}^{\prime} \delta+\varepsilon_{a s t} .
$$

The standard deviation of relative bids is modeled as a function of the ECE policy dummies and a set of auction and business characteristics $\left(z_{\text {ast }}\right)$. We estimate the model across all auctions and for the asphalt and bridge work auctions separately. The data only contain auctions with four or more bidders because we need to construct an auction-specific standard deviation. We also use the range of relative bids (maximum bid-minimum bid)/(engineering estimate) in an auction as an alternative measure of the dependent variable. Since, the model is estimated at the auction level, the independent variables contained in $z_{\text {ast }}$ include the auction-level and business condition controls but omit the bidder-level variables. Table 6 presents these results. There are two main findings. First, the results across all auctions show a substantial decline in both the standard deviation and the range of relative bids in Oklahoma after the ECE policy change (columns (1) and (4)). Second, when comparing asphalt to bridge work auctions, the declines in the standard deviation and the range are larger in magnitude for the bridge projects. This is as expected if the release of information is reducing the uncertainty in common costs and common costs uncertainty is more prevalent in bridge projects.

\subsection{Quantile regression analysis}

In our analysis of bids, we have considered up to this point differences in the expected value, the variance and the range of values. We will now show that the level of bids is consistently lower in Oklahoma than in Texas not only in expectation but across the bidding distributions. We can thus provide additional evidence, beyond the graphs and the 
Table 5

Panel-fixed effects differences-in-differences estimates for asphalt and bridge projects

\begin{tabular}{|c|c|c|c|c|}
\hline \multirow[t]{2}{*}{ Variable } & \multicolumn{2}{|l|}{ Asphalt projects } & \multicolumn{2}{|l|}{ Bridge projects } \\
\hline & $\begin{array}{l}\text { Relative bids } \\
\text { (1) }\end{array}$ & $\begin{array}{l}\text { Relative winning bids } \\
\text { (2) }\end{array}$ & $\begin{array}{l}\text { Relative bids } \\
\text { (3) }\end{array}$ & $\begin{array}{l}\text { Relative winning bids } \\
\text { (4) }\end{array}$ \\
\hline Oklahoma bids $\left(\beta_{1}\right)$ & $.036(.058)$ & $.036(.127)$ & $.019(.153)$ & $.299 * *(.104)$ \\
\hline $\begin{array}{l}\text { Bids from November } 1999 \text { to March } \\
2000\left(\beta_{2}\right)\end{array}$ & $-.027(.016)$ & $-.014(.026)$ & $-.043(.033)$ & $.005(.073)$ \\
\hline $\begin{array}{l}\text { Oklahoma bids from November } 1999 \text { to March } \\
2000\left(\beta_{3}\right)\end{array}$ & $.150 * *(.041)$ & $.093 * *(.037)$ & $-.003(.055)$ & $-.059(.086)$ \\
\hline Bids after March $2000\left(\beta_{4}\right)$ & $-.030 * *(.012)$ & $-.003(.015)$ & $-.029(.030)$ & $.021(.047)$ \\
\hline Oklahoma bids after March $2000\left(\beta_{5}\right)$ & $.012(.019)$ & $-.010(.022)$ & $-.096^{* *}(.039)$ & $-.090 *(.053)$ \\
\hline Number of bidders & $-.018 * *(.002)$ & $-.030 * *(.004)$ & $-.018 * *(.004)$ & $-.022 * *(.005)$ \\
\hline Capacity utilized & $.018(.012)$ & $.001(.021)$ & $-.012(.024)$ & $.052(.042)$ \\
\hline Distance to the project location & $.008 * *(.003)$ & $.001(.003)$ & $-.002(.012)$ & $.009(.009)$ \\
\hline Average rivals winning to plan holder ratio & $-.063(.067)$ & $-.129 *(.074)$ & $-.011(.236)$ & $-.226(.174)$ \\
\hline Closest rival's distance to the project location & $-.005^{* *}(.002)$ & $-.001(.003)$ & $-.001(.004)$ & $.005(.005)$ \\
\hline Rivals minimum backlog & $-.001 * *(.000)$ & $-.001(.001)$ & $.000(004)$ & $-.000(.002)$ \\
\hline Seasonally unadjusted unemployment rate & $-.006(.005)$ & $.000(.008)$ & $-.021 *(.011)$ & $-.017(.012)$ \\
\hline Three month average of the real volume of projects & $-.009(.014)$ & $-.008(.013)$ & $-.058 * *(.026)$ & $-.026(.038)$ \\
\hline $\begin{array}{l}\text { Three month average of the number of building } \\
\text { permits }\end{array}$ & $.100 * *(.035)$ & $.032(.061)$ & $-.034(.080)$ & $.039(.078)$ \\
\hline Number of observations & 3962 & 1052 & 4569 & 1011 \\
\hline $\operatorname{Adj}-R^{2}$ & .177 & .289 & .120 & .181 \\
\hline
\end{tabular}

**Denotes statistical significance at the 5\% level and * denotes statistical significance at the $10 \%$ level. Robust clustered standard errors using firm-level clusters are in parentheses. All regressions include firm-level fixed effects and 11 monthly dummy variables. 
Table 6

Estimates of bid dispersion model

\begin{tabular}{|c|c|c|c|c|c|c|}
\hline \multirow[t]{2}{*}{ Variable } & \multicolumn{3}{|c|}{ Standard deviation } & \multicolumn{3}{|l|}{ Range } \\
\hline & $\begin{array}{l}\text { All projects } \\
\text { (1) }\end{array}$ & $\begin{array}{l}\text { Asphalt projects } \\
\text { (2) }\end{array}$ & $\begin{array}{l}\text { Bridge projects } \\
\text { (3) }\end{array}$ & $\begin{array}{l}\text { All projects } \\
\text { (4) }\end{array}$ & $\begin{array}{l}\text { Asphalt projects } \\
\text { (5) }\end{array}$ & $\begin{array}{l}\text { Bridge projects } \\
\text { (6) }\end{array}$ \\
\hline Oklahoma bids $\left(\beta_{1}\right)$ & $.054 * *(.013)$ & $.036 * *(.014)$ & $.090 * *(.026)$ & $.130^{* *}(.032)$ & $.077 * *(.035)$ & $.221^{* *}(.066)$ \\
\hline $\begin{array}{l}\text { Bids from November } 1999 \\
\text { to March } 2000\left(\beta_{2}\right)\end{array}$ & $.017(.015)$ & $.008(.014)$ & $-.004(.027)$ & $.040(.040)$ & $.007(.031)$ & $-.004(.069)$ \\
\hline $\begin{array}{l}\text { Oklahoma bids from } \\
\text { November } 1999 \text { to March } \\
2000\left(\beta_{3}\right)\end{array}$ & $-.044(.029)$ & $.047(.054)$ & $-.015(.063)$ & $-.125^{*}(.071)$ & $.102(.131)$ & $-.065(.143)$ \\
\hline Bids after March $2000\left(\beta_{4}\right)$ & $.014 *(.007)$ & $.002(.008)$ & $.013(.019)$ & $.031 *(.018)$ & $.003(.019)$ & $-.029(.048)$ \\
\hline $\begin{array}{l}\text { Oklahoma bids after } \\
\text { March } 2000\left(\beta_{5}\right)\end{array}$ & $-.044 * *(.015)$ & $-.030 *(.016)$ & $-.061 *(.031)$ & $-.107 * *(.037)$ & $-.064(.040)$ & $-.151 * *(.075)$ \\
\hline Number of bidders & $-.004 * *(.002)$ & $-.005 * *(.002)$ & $-.012 * *(.004)$ & $.010 * *(.004)$ & $.002(.004)$ & $-.003(.010)$ \\
\hline $\begin{array}{l}\text { Seasonally unadjusted } \\
\text { unemployment rate }\end{array}$ & $.001(.004)$ & $.001(.005)$ & $.004(.010)$ & $.003(.011)$ & $.001(.012)$ & $.014(.024)$ \\
\hline $\begin{array}{l}\text { Three month average of } \\
\text { the real volume of projects }\end{array}$ & $.028 * *(.010)$ & $.005(.019)$ & $.028(.020)$ & $.067 * *(.025)$ & $.015(.045)$ & $.066(.047)$ \\
\hline $\begin{array}{l}\text { Three month average of } \\
\text { the number of building } \\
\text { permits }\end{array}$ & $.013(.037)$ & $.013(.040)$ & $-.096(.074)$ & $.047(.093)$ & $.036(.096)$ & $-.224(.189)$ \\
\hline Number of observations & 1651 & 460 & 629 & 1651 & 460 & 629 \\
\hline $\operatorname{Adj}-R^{2}$ & .111 & .052 & .080 & .123 & .026 & .070 \\
\hline
\end{tabular}

**Denotes statistical significance at the $5 \%$ level and * denotes statistical significance at the $10 \%$ level. Robust standard errors are in parentheses. All regressions include a constant term and 11 monthly dummy variables. Regression in columns (1) and (4) includes five project-type dummy variables. 
preceding statistical analysis, that the aggressive bidding behavior after the policy change is not due to a truncation of the distribution of bids at the upper end (for high cost bidders) but due to an informational effect that persistently affects bidding behavior at every level. This fact can be formalized in the analysis of the quantile regression model (see Koenker and Bassett, 1982) that follows.

This model allows us to estimate differences in the distribution of bids across bidders in Oklahoma and Texas before and after the policy change more accurately while taking into account other factors that contribute to the variability of bids. The advantage of employing quantile regression analysis at this point is that it allows a detailed examination of the difference between the distributions of bids not only at their mean level that could somewhat be driven by outliers but at the median, the 25 th and 75 th percentiles. The results of these estimations are presented in Table 7. The dependent variable in all regressions is the relative bid. The analysis employs similar specifications to those reported in column (1) of Table 3 and columns (1) and (3) of Table 5 (without a full set of the fixed effects). ${ }^{20}$ The estimated coefficient of $\beta_{5}$ on the difference between the overall bids in Oklahoma and Texas after the policy change is the same in the .25 and .75 quantiles. The difference across the three quantiles tested from the models in columns (1) through (3) of Table 7 is statistically insignificant $(F(2,13216)=.350)$. The bids in Oklahoma are lower than those in Texas by $4.6 \%$ at the .50 quantile, holding everything else constant. That difference is almost the same as the expected difference reported in Table 3 but it represents the effect at the median level of bids which is less affected by outliers. Notice from columns (4) through (6) of Table 7 that the difference in the estimate of $\beta_{5}$ is statistically insignificant for asphalt work across the three quartiles and shows uniformly no difference in the bidding level across the two states after the policy change. When considering bridge work, there is no statistically significant difference in the estimate of $\beta_{5}$ across the quantiles, but all coefficients are statistically significant within each model signifying a large and persistent difference in the bidding behavior across the two states after the policy was implemented. For bridge projects, the median bid in Oklahoma after the policy change is $13.6 \%$ lower than in Texas.

\subsection{Robustness analysis}

In the remaining part of the section, we estimate a number of alternative specifications in order to examine the robustness of our results. First, we consider the possibility that the standard errors in our model may be underestimated. While we have employed clustered standard errors throughout the paper to address the problems of within group correlation raised by Moulton (1990). Bertrand et al., (2004) raise the point that clustered standard errors are biased downward in panel data if serial correlation is present. One approach that Bertrand, Duflo and Mullainathan recommend is to collapse the time dimension of the data down to two periods - pre- and post-policy change. In our application, we aggregate the pre- and post-ECE policy data by firm and project type. Aggregation by firm within project types will allow for differences in response to the ECE policy change across project types seen in Table 5, while still collapsing the time dimension down into two periods. We

\footnotetext{
${ }^{20}$ The model contains a set of individual firm dummies for the largest 35 firms in the sample. The remaining firms are modeled as a common intercept. We restricted the firm dummies to a manageable set for computation reasons.
} 
Table 7

Quantile regression estimates for relative bids

\begin{tabular}{|c|c|c|c|c|c|c|c|c|c|}
\hline \multirow[t]{2}{*}{ Variable } & \multicolumn{3}{|l|}{ Base model } & \multicolumn{3}{|c|}{ Asphalt projects } & \multicolumn{3}{|l|}{ Bridge projects } \\
\hline & $\begin{array}{l}.25 \\
(1)\end{array}$ & $\begin{array}{l}.50 \\
(2)\end{array}$ & $\begin{array}{l}.75 \\
(3)\end{array}$ & $\begin{array}{l}.25 \\
(4)\end{array}$ & $\begin{array}{l}.50 \\
(5)\end{array}$ & $\begin{array}{l}.75 \\
(6)\end{array}$ & $\begin{array}{l}.25 \\
(7)\end{array}$ & $\begin{array}{l}.50 \\
(8)\end{array}$ & $\begin{array}{l}.75 \\
(9)\end{array}$ \\
\hline Oklahoma bids $\left(\beta_{1}\right)$ & $-.032 * *(.010)$ & $-.019 *(.011)$ & $-.018(.014)$ & $-.002(.016)$ & $-.013(.017)$ & $-.035(.022)$ & $-.038 *(.021)$ & $.004(.020)$ & $.019(.031)$ \\
\hline $\begin{array}{l}\text { Bids from November } 1999 \\
\text { to March } 2000\left(\beta_{2}\right)\end{array}$ & $-.027 * *(.010)$ & $-.006(.016)$ & $.019(.025)$ & $-.022(.017)$ & $-.015(.021)$ & $-.005(.021)$ & $-.029(.022)$ & $.003(.023)$ & $.008(.051)$ \\
\hline $\begin{array}{l}\text { Oklahoma bids from } \\
\text { November } 1999 \text { to March } \\
2000\left(\beta_{3}\right)\end{array}$ & $.048 * *(.018)$ & $.029(.020)$ & $.012(.029)$ & $.113 * *(.023)$ & $.111 * *(.036)$ & $.169^{* *}(.055)$ & $.032(.039)$ & $-.017(.037)$ & $-.010(.073)$ \\
\hline $\begin{array}{l}\text { Bids after March } 2000\left(\beta_{4}\right) \\
\text { Oklahoma bids after March } \\
2000\left(\beta_{5}\right)\end{array}$ & $\begin{array}{l}-.026^{* *}(.006) \\
-.038^{* *}(.010)\end{array}$ & $\begin{array}{l}-.025^{* *}(.008) \\
-.046^{* *}(.011)\end{array}$ & $\begin{array}{l}-.034 * *(.011) \\
-.044 * *(.014)\end{array}$ & $\begin{array}{l}-.016(.011) \\
-.003(.015)\end{array}$ & $\begin{array}{c}-.041 * *(.012) \\
.028(.017)\end{array}$ & $\begin{array}{c}-.027 *(.014) \\
.016(.024)\end{array}$ & $\begin{array}{c}.002(.011) \\
-.104 * *(.018)\end{array}$ & $\begin{array}{c}.022(.014) \\
-.136 * *(.019)\end{array}$ & $\begin{array}{l}-.012(.021) \\
-.122^{* *}(.027)\end{array}$ \\
\hline $\begin{array}{l}\text { Number of observations } \\
\text { Pseudo- } R^{2}\end{array}$ & $\begin{array}{c}13,282 \\
.043\end{array}$ & $\begin{array}{c}13,282 \\
.041\end{array}$ & $\begin{array}{c}13,282 \\
.054\end{array}$ & $\begin{array}{l}3962 \\
.042\end{array}$ & $\begin{array}{c}3962 \\
.047\end{array}$ & $\begin{array}{l}3962 \\
.057\end{array}$ & $\begin{array}{r}4569 \\
.066\end{array}$ & $\begin{array}{c}4569 \\
.057\end{array}$ & $\begin{array}{r}4569 \\
.072\end{array}$ \\
\hline
\end{tabular}

**Denotes statistical significance at the $5 \%$ level and * denotes statistical significance at the $10 \%$ level. The reported standard errors are bootstrap standard errors using 100 replications. All regressions include a constant term, 35 large firm dummies, and 11 monthly dummy variables. Regression in columns (1-3) includes five project-type dummy variables. Hypothesis test results for $H_{\mathrm{o}}: \beta_{5}^{.25}=\beta_{5}^{.50}=\beta_{5}^{.75}$.

Base model: $\mathrm{F}(2,13216)=.350$.

Asphalt projects: $F(2,3910)=1.690$

Bridge projects: $\mathrm{F}(2,4534)=1.420$. 
require each firm to be bidding in both periods in order to estimate the fixed effects models and we drop the transition period data. Column (1) of Table 8 presents these results. The results are consistent with the model reported in Table 3 in terms of sign and statistically significance though the magnitude of the effect is substantially larger here. This increase in magnitude is most likely due to the fact that by aggregating across auctions our other control variables are less effective at controlling for differences in bidding across firms.

A second issue is whether the ECE policy variable is just picking up a declining trend in Oklahoma relative bids over time. To examine this matter, we estimate the relative bid model using only data from the pre-ECE policy change period and include trend variables to measure the trends in relative bids in Oklahoma and Texas over this period. The model includes an overall trend term and the trend term interacted with a dummy variable for Oklahoma auctions to test for cross-state differences in trend. The second column of Table 8 contains these results. The estimated trend terms are not individually statistically significant and show no statistical difference between Oklahoma and Texas. Hence, Oklahoma's relative bids were not trending downward prior to the ECE policy change either in an absolute sense or relative to Texas.

We also estimated our models altering our clustering approach. Throughout the paper, we have chosen to cluster by firm. An alternative approach is to cluster by auction. This raises the number of clustering groups significantly (3608 clusters) and subsequently decreases the number of observations per group. The third column of Table 8 provides these results. The ECE remains statistically significant and the standard errors are almost identical under both clustering approaches.

A third test that we perform deals with a special group of auctions in Oklahoma that we refer to as repeated auctions. Repeated auctions are auctions of projects that failed to be auctioned off in an initial attempt. For these projects, bidders have a very good idea of the engineering estimate in all periods because in the initial round the engineering estimate is released and, thus, the effect of the change in ECE information policy in this sub-sample should be small. We perform our empirical test by adding the repeated Oklahoma auction data to our Oklahoma-Texas sample and estimate the panel-data differences-in-differences model with a set of dummy variables that control for bidding in repeated auctions. If the repeated auctions have the same pattern in coefficients as the non-repeated auctions in Oklahoma, then this would suggest that the time period effects may be picking up some other shocks that are specific to Oklahoma but not related to the ECE information policy change. The fourth column of Table 8 reports the results of models that include the repeated auctions in our empirical analysis. The repeated auction coefficients indicate no decline in bids in the repeated auction after the change in ECE policy. A joint statistical test of the three coefficients cannot reject the hypothesis that bidding in the repeated auctions is no different than in Texas auctions $(F(3,491)=.300)$. However, one should be cautious here in over-interpreting the repeated auction test as a comparison to a randomly selected control group. This is clearly not the case. The repeated auctions represent projects that failed to be awarded in an initial auction primarily because the submitted bids were too high or because no firms bid on the project. This lower level of competition in these auctions is reflected in the bidding statistics presented in Table 2c.

The present specification is conditioned on detailed information available to bidders about current auctions and previous bidding activity. In a paper by Jofre-Bonet and Pesendorfer (2003) that also analyzes highway procurement auctions, they include controls for future lettings which might affect the intensity of competition in current period 
Table 8

Alternate specifications and robustness checks

\begin{tabular}{|c|c|c|c|c|c|c|}
\hline \multirow[t]{3}{*}{ Variable } & \multirow{3}{*}{$\begin{array}{l}\text { Pre-relative } \\
\text { bids - averaged } \\
\text { by period and } \\
\text { project types } \\
\text { (1) }\end{array}$} & \multicolumn{5}{|l|}{ Relative bids } \\
\hline & & $\begin{array}{l}\text { Time trend } \\
\text { analysis }\end{array}$ & $\begin{array}{l}\text { Standard errors } \\
\text { clustered by } \\
\text { auctions }\end{array}$ & $\begin{array}{l}\text { Repeated } \\
\text { auctions }\end{array}$ & $\begin{array}{l}\text { Future bid } \\
\text { lettings }\end{array}$ & $\begin{array}{l}\text { Expected } \\
\text { number of } \\
\text { bidders }\end{array}$ \\
\hline & & (2) & & (4) & (5) & \\
\hline Oklahoma bids $\left(\beta_{1}\right)$ & $.006(.091)$ & $-.100(.057)$ & $.002(.038)$ & $-.005(.065)$ & $.004(.065)$ & $-.006(.063)$ \\
\hline Bids from November 1999 to March $2000\left(\beta_{2}\right)$ & & & $-.034 *(.020)$ & $-.035^{* *}(.013)$ & $-.031 * *(.013)$ & $-.037^{* *}(.013)$ \\
\hline $\begin{array}{l}\text { Oklahoma bids from November } 1999 \text { to March } \\
2000\left(\beta_{3}\right)\end{array}$ & & & $.038(.033)$ & $.042 *(.023)$ & $.033(.024)$ & $.040^{*}(.023)$ \\
\hline Bids after March $2000\left(\beta_{4}\right)$ & $-.083 *(.027)$ & & $-.034 * *(.013)$ & $-.033^{* *}(.010)$ & $-.033^{* *}(.010)$ & $-.040 * *(.010)$ \\
\hline Oklahoma bids after March $2000\left(\beta_{5}\right)$ & $-.109 *(.037)$ & & $-.050 * *(.021)$ & $-.048 * *(.020)$ & $-.056 *(.020)$ & $-.045^{* *}(.010)$ \\
\hline Time & & $.001(.001)$ & & & & \\
\hline Time* Oklahoma bids & & $.000(.001)$ & & & & \\
\hline Repeated auctions & & & & $-.020(.064)$ & & \\
\hline Repeated auctions in Oklahoma from 1999:11 to & & & & $.042(.054)$ & & \\
\hline $2000: 3$ & & & & & & \\
\hline Repeated auctions in Oklahoma after $2000: 3$ & & & & $.023(.043)$ & & \\
\hline Future average real value of projects & & & & & $.005(.009)$ & \\
\hline Future number of projects & & & & & $-.034 *(.015)$ & \\
\hline Expected number of bidders & & & & & & $-.010^{* *}(.001)$ \\
\hline Number of observations & 942 & 4088 & 13,282 & 13,684 & 13,282 & 13,282 \\
\hline $\operatorname{Adj}-R^{2}$ & .293 & .181 & .136 & .142 & .137 & .132 \\
\hline
\end{tabular}

**Denotes statistical significance at the $5 \%$ level and * denotes statistical significance at the $10 \%$ level. All regressions include firm-level fixed effects and five projecttype dummy variables. Columns (3-6) include 11 monthly dummy variables. All regressions other than in column (3) report robust clustered standard errors using firm-level clusters. In column (3) robust clustered standard errors using auction level clusters are in parentheses. 
auctions. In order to empirically assess whether changes in the frequency of future bid lettings between states is affecting our results, we re-estimate the relative bid model of Table 3 incorporating two new variables that measure future bid letting activity-the number of projects and the average size of projects to be let in the next 3 months. The results are reported in column (5) of Table 8. Our estimates of the ECE policy parameters are robust to this change in specification and this would be true across the other models presented in the paper.

A last exercise we perform considers the possibility that the actual number of bidders may not be the best measure of potential competition in these settings (Hendricks et al., 2003). In our case, the actual number of bidders is not known to participants. To see the sensitivity of our results to the assumption that the number of bidders is given, we reestimate the model replacing the number of bidders with a variable that measures the expected number of bidders. The expected number of bidders is constructed using information on past bidding history of all plan holders in an auction. The number of plan holders and the identity of the plan holders are known to all bidders before bids are submitted. For each plan holder at time $t$, we sum up their past number of bids and divide this by their past number of plans held. This gives a probability of bidding for each plan holder. Then for an auction at time $t$, we sum across these participation probabilities for all plan holders in an auction and this yields our measure of the expected number of bidders. Since the identity of the plan holders is known to all potential bidders, an estimate of the expected number of bidders can be constructed by bidders in such a way prior to the bid submission. Column (6) of Table 8 presents the results. The coefficient on the expected number of bidders is somewhat smaller in magnitude than that reported in Table 3 though it remains negative and statistically significant. More importantly, our results on the ECE policy variable remain unchanged to this modification in the specification. Finally, estimated models (not shown) on the asphalt and bridge work project samples using expected number of bidders instead of the number of bidders are also consistent with findings reported in Table 5.

\section{Information policy effects on the number of bidders}

While the above analysis has examined the direct effect of change in ECE policy on bids, another channel by which the policy change could affect bidding is through the number of bidders. When the state reveals the ECE, it provides additional information about the cost and the likely reserve price of the project. If bidders base their decision to submit a bid on this type of information, then the number of bidders is likely to be affected by the ECE, as well.

Our current model, assumes that the overall effect of the change in the ECE policy is measured by the estimate of $\beta_{5}$. However, if the ECE policy variable also affects the number of bidders, then our expression for the policy effect on bids should be

$$
\begin{aligned}
& E\left[y \mid x, D_{s}, A_{t}=1\right]-E\left[y \mid x, D_{s}=1, A_{t}, T_{t}=0\right]-\left[E\left[y \mid x, D_{s}=0, A_{t}=1\right]-E\left[y \mid x, D_{s}, A_{t}, T_{t}=0\right]\right] \\
& =\beta_{5}+\beta_{n}\left[E\left[n \mid D_{s}, A_{t}=1\right]-E\left[n \mid D_{s}=0, A_{t}=1\right]\right],
\end{aligned}
$$

where $\beta_{n}$ is the coefficient on the number of bidders in the relative bids model and $E\left[n \mid D_{s}\right.$, $\left.A_{t}=1\right]-E\left[n \mid D_{s}=0, A_{t}=1\right]$ is the difference in the average number of bidders in Texas 
and Oklahoma due to the ECE policy change. In order to estimate the effect of the ECE policy change on the average number of bidders, we estimate a count-data model (Poisson) of the number of bidders on the ECE policy variables along with a set of control variables. These control variables include project size, detailed project location dummies, projecttype dummies, monthly dummies, and business condition variables. We also estimate a similar model using the number of plan holders (i.e., the number of potential bidders). Columns (1) and (2) of Table 9 report the results from these count data models for the number of plan holders and number of bidders, respectively. ${ }^{21}$ The unit of observation here is an auction. Focusing on the post-ECE policy change parameter, we see that the post-ECE policy parameter is not statistically significant in the number of plan holders' equation. There is, however, a statistically significant effect on the number of bidders. The number of bidders decreases in Oklahoma relative to Texas in the post-ECE policy change period. The magnitude of the effect, calculated as the average response, is a decline of .440 bidders in Oklahoma. ${ }^{22}$ It should be noted that this is the relative average response in Oklahoma compared to Texas. In fact, in both Texas and Oklahoma the absolute number of bidders rises in the post-ECE policy change period compared to the pre-ECE policy change period. Plugging the estimates from the relative bid model in Table 3 and the average response calculated from the Poisson model into the expression (5) yields an effect of $-.043=\{-.050-.015 \times(-.440)\}$. We test the statistical significance of the overall effect using a Wald test. The $\chi^{2}$ statistic from this test is 4.42 with a $p$-value of $.036 .{ }^{23}$ Hence, our overall estimate of the effect of the ECE policy change on relative bids remains statistically significant at the $5 \%$ level.

While the main concern of the paper is not on the number bidders, if the number of bidders is endogenous it may affect our estimates of the ECE policy parameters, the estimate of $\beta_{n}$ from the original equation, and therefore the estimate of the overall effect the ECE policy change.

Extending the theory presented in Section 2, assume that the bidders have to incur a fixed bid preparation cost $e$ to learn information about their private signals. The actual number of participants depends on the bid preparation cost and the expected surplus from participation. Following Levin and Smith (1994) the equilibrium entry probability $q^{*}$ will be determined by the following zero profit condition:

$$
e=\sum_{n=1}^{N}\left[\left(\begin{array}{c}
N-1 \\
n-1
\end{array}\right)\left(q^{*}\right)^{n-1}\left(1-q^{*}\right)^{N-n} E[\pi \mid n, N]\right],
$$

\footnotetext{
${ }^{21}$ An assumption of the Poisson model is that mean and variance of the distribution of counts is the same. In our application, the mean and variance of the number of bids are almost identical being 3.70 and 3.78 , respectively. In a test of overdispersion, we cannot reject the null hypothesis of no overdispersion. This is not true in the case of the number of plan holders where overdisperson is a problem. However, we do not use the estimates from the Poisson model on the number of plan holders in our calculation of the overall effect.

${ }^{22}$ The average response for the effect of post-ECE policy change on the number of bidders is calculated as the $\hat{a}_{5} \times N^{-1} \sum_{a} \exp \left(x_{i}^{\prime} \hat{a}\right)$ where the $\hat{a}$ 's are parameters estimated in the Poisson model.

${ }^{23} \mathrm{We}$ estimate the relative bids and Poisson models using a seemingly unrelated regression approach that allows for clustered standard errors and between equation covariance in parameter estimates. Given that the Poisson model is at the auction level, the models are estimated with clustering at the auction level. Clustering using auctions actually increases the standard errors in the relative bid model slightly more than when using firm clusters. This is reported above in Table 8.
} 
Table 9

Number of bidders analysis

\begin{tabular}{|c|c|c|c|c|}
\hline \multirow[t]{2}{*}{ Variable } & \multicolumn{2}{|l|}{ Poisson } & \multicolumn{2}{|l|}{ Relative bids } \\
\hline & $\begin{array}{l}\text { Number of plan } \\
\text { holders } \\
\text { (1) }\end{array}$ & $\begin{array}{c}\text { Number of bidders } \\
\text { (2) }\end{array}$ & $\begin{array}{l}\text { Base model } \\
\text { (3) }\end{array}$ & $\begin{array}{l}\text { Instrumented with } \\
\text { number of plan } \\
\text { holders } \\
\text { (4) }\end{array}$ \\
\hline $\begin{array}{l}\text { Oklahoma bids }\left(\beta_{1}\right) \\
\text { Bids from November } 1999 \text { to March } 2000\left(\beta_{2}\right) \\
\text { Oklahoma bids from November } 1999 \text { to March } 2000\left(\beta_{3}\right) \\
\text { Bids after March } 2000\left(\beta_{4}\right) \\
\text { Oklahoma bids after March } 2000\left(\beta_{5}\right) \\
\text { Log of engineering estimate } \\
\text { Log of engineering estimate } \\
\text { Number of bidders } \\
\text { Capacity utilized } \\
\text { Distance to the project location } \\
\text { Average rivals winning to plan holder ratio } \\
\text { Closest rival's distance to the project location } \\
\text { Rivals minimum backlog } \\
\text { Seasonally unadjusted unemployment rate } \\
\text { Three month average of the real volume of projects } \\
\text { Three month average of the number of building permits } \\
\text { First stage instrument } \\
\text { Number of plan holders }\end{array}$ & $\begin{array}{c}.069(.048) \\
-.012(.064) \\
.161 * *(.027) \\
-.049(.354) \\
-.298 * *(.067) \\
.015 * *(.002)\end{array}$ & $\begin{array}{c}.100 * *(.048) \\
-.019(.067) \\
.202 * *(.026) \\
-.119^{* *}(.037) \\
-.210 * *(.063) \\
.010 * *(.002)\end{array}$ & $\begin{array}{c}.002(.066) \\
-.034^{* *}(.013) \\
.038(.024) \\
-.034^{* *}(.010) \\
-.050^{* *}(.020) \\
\\
-.015^{* *}(.002) \\
.012(.011) \\
.006(.004) \\
-.058(.081) \\
.001(.002) \\
-.000(.001) \\
-.012 * *(.005) \\
-.023 *(.012) \\
.034(.036)\end{array}$ & $\begin{array}{c}-.015 * *(.002) \\
.012(.011) \\
.006(.004) \\
-.058(.083) \\
.001(.002) \\
-.000(.001) \\
-.012 * *(.005) \\
-.023 * *(.009) \\
.034(.037) \\
.412 * *(.008)\end{array}$ \\
\hline $\begin{array}{l}\text { Number of observations } \\
\text { Adj- } R^{2} \\
\text { Wald } \chi^{2} \\
\text { Hausman test ( } p \text {-value) }\end{array}$ & 1841.17 & $\begin{array}{l}3634 \\
996.22\end{array}$ & $\begin{array}{r}13,282 \\
.136\end{array}$ & $\begin{array}{c}13,282 \\
.136\end{array}$ \\
\hline
\end{tabular}

**Denotes statistical significance at the $5 \%$ level and * denotes statistical significance at the $10 \%$ level. In columns (1) and (2) robust standard errors are in parentheses. In columns (3) and (4) robust clustered standard errors using firm-level clusters are in parentheses. The Poisson models in columns (1) and (2) include 14 project location dummies, five project-type dummy variables, and 11 monthly dummy variables. The models in columns (3) and (4) include firm-level fixed effects, five project-type dummy variables, and 11 monthly dummy variables. 
where $E[\pi \mid n, N]$ is the conditional expected surplus or profit of a bidder measured by the difference between the lowest and the second lowest statistic drawn from the bidding distribution. The condition says that the entry probability is determined so that ex ante, the benefits from participation equal the bid preparation cost. The number of bidders then is determined by $n=q^{*} N$.

With that in mind, we need to determine how the information release will affect bidding behavior in this environment. There are two possible effects of the information release. Ceteris paribus, the information release reduces the winner's curse and induces more aggressive bidding behavior. This is a direct effect. There is also an indirect effect arising through the change in the number of bidders. Consider the entry condition above. The aggressive bidding behavior will reduce the surplus $E[\pi \mid n, N]$ of bidders. With reduced benefits from participation a smaller number of bidders will enter the auction weakening competition. Decreased competition leads to less aggressive bidding since the probability of obtaining the item with fewer bidders is going to be higher (competitive effect). As the number of potential bidders decreases the winner's curse becomes even less severe and rational bidders will bid more aggressively (winner's curse effect). Hong and Shum (2002), Bordley and Harstad (1996), Krishna and Morgan (1997), Bulow and Klemperer (2002) and others have considered the effect of an increase in the number of bidders on bidding strategies. They have also made the distinction between the competitive effect and the winner's curse effect. A decrease in the number of bidders will induce less aggressive bidding due to the competitive effect and more aggressive bidding due to the winner's curse effect. The end result depends on the relative strength of these factors.

With endogenous entry, the information release will induce more aggressive bidding due to the direct winner's curse effect and an additional ambiguous bidding effect due to the possibility of lower entry. If the competitive effect of reduced entry outweighs the winner's curse effect on the bidding strategy the overall effect of the information release will be weaker in this model relative to the model of exogenous entry. If the winner's curse effect outweighs the competitive effect, the information release will lead to more aggressive bidding behavior in the endogenous entry model compared to the exogenous entry model.

To allow for endogeneity in the number of bidders empirically, we re-estimate the model using instrumental variable techniques where our instrument for the number of bidders is the number of plan holders. There are two requirements for a valid instrument in this application. It must be correlated with the number of bidders and uncorrelated with the error term in the relative bids equation. The number of plan holders is certainly strongly correlated with the number of bidders in an auction since it identifies the maximum number of bidders that appear in an auction. With respect to the correlation between the number plan holders and the error term, we argue the number of plan holders will be relatively uncorrelated with the error term in the bidding equation.

As we mentioned above, the number of plan holders and the identity of plan holders is known to all bidders prior to bid submission. So, the number of plan holders is clearly not affected by the bids submitted. Now consider an error structure that would cause us problems. Let the error term in Eq. (3) be $\varepsilon_{i a t}=\mu_{i}+\mu_{a}+\mu_{i a t}$, where $\mu_{i}$ is a firm-specific error component, $\mu_{a}$ is an auction-specific error component and $\mu_{\text {iat }}$ is a white noise component. The firm effects already included in the model control for the firm-specific component. The model cannot include auction-specific effects because our interest is in estimating the effects of the ECE policy variables on bidding and there is no within auction variation is the ECE policy variables. The endogeneity in the number of bidders arises if 
the $\operatorname{Cov}\left(\right.$ number of bidders, $\left.\mu_{a}\right) \neq 0$. This says there is some auction-specific factor that is uncontrolled for in the regression and is correlated with the number of bids. For example, this could be due to some specialized input required to complete a project that affects both the level of bids and number of bidders. However, $\mu_{a}$ is likely to be observed by a potential bidder only after the firm purchases a plan and, hence, there should be little correlation between $\mu_{a}$ and the decision to purchase a plan. Moreover, plans are very inexpensive costing around $\$ 25$ for a project, so there would be little incentive for a firm to formulate an independent estimate of $\mu_{a}$ without purchasing a plan. Now it is true that when bidders see a high (low) number of plan holders they may bid more (less) aggressively but they do so only because the number of bidders is likely to be higher (lower) when there are more (less) plan holders in an auction. We can think of no other reason why the number of plan holders should affect the bids submitted except through its influence on the number of bidders. Therefore, we believe that the number of plan holders is a valid instrument.

The IV model is estimated using two-stage least squares with clustered standard errors. The third and fourths column of Table 9 show the results of this exercise. Column (4) presents the IV results while column (3) shows the results from the basic OLS model discussed earlier for comparison purposes. As one can see, there is little difference between the OLS and IV results. The Hausman test reported at the bottom of the table indicates we cannot reject the null hypothesis that the OLS and IV models yield similar estimates. The results also show, as expected, that the number of plan holders is highly correlated with the number of bidders in the first stage regression. There are two main conclusions we draw from this IV exploration. First, it is reasonable to use our estimate of $\beta_{n}$ from the OLS in calculating the overall effect of the ECE policy change on relative bids. Second, the sign and magnitude of the parameters on the ECE policy variables are insensitive to the choice of IV or OLS estimation techniques.

\section{Conclusion}

This paper contributes to the empirical literature on auctions by providing an examination of the impact of the release of information on bidding behavior in procurement auctions. We provide the first empirical test of the theory by Milgrom and Weber (1982) using a natural experiment and field auction data. Our analysis of the bidding data produced three main empirical findings. First, in comparison to Texas auctions, the average bid in Oklahoma declines after the change in ECE policy. Second, bids drop sharply in bridge work but not in asphalt projects. Third, the variation in bids falls after the change in ECE policy and the magnitude of this decline is larger for bridge projects compared to asphalt projects. These three results are in agreement with the predictions of the theory. The release of seller information generally leads to lower bids. In Oklahoma, these lower average bids do not result in lower winning bids across all projects and hence do not result in lower procurement costs, on average. This raises the concern that the release of information may be affecting only the upper end of bid distribution. However, the quantile regression results along with the basic patterns observed in Fig. 1 show that the effect of the ECE policy variable is relatively uniform across the quantiles. Moreover, in bridge work where we expected to see a larger impact, we do observe a decline in winning bids that is similar in magnitude to the decline in the average bid. Even after we account for implicit effects through a potential change in the number of bidders submitting bids, the effect of the ECE policy change on relative bids remains strong and 
statistically significant. In addition, we find no evidence that the change in information policy led to an increase in relative bids in two and half years since the policy changed. This is an important outcome to rule out as federal and state transportation officials have raised concerns that the releasing of the ECE estimate prior to bid letting may lessen competition.

In fact, throughout the paper it was assumed that the competitive environment is maintained. Clearly, collusion has been a problem in this industry in the past (Porter and Zona, 1993) and the federal government has put together guidelines for the detection and prevention of collusive behavior. With regard to the state's ECE, the guidelines recommend that states not make the information available prior to the award of the contract. The rationale for this recommendation is that the release of the ECE may "encourage and facilitate bid rigging." 24 If an open information policy facilitated collusive behavior, then this would work to mute the effects reported above. Alternatively, if the release of information reduced the benefits from sharing information by an existing cartel, then the open information policy might reduce the likelihood of cartelization resulting in increased competition. Such a possibility would blur the interpretation of our results. Nonetheless, our results support the theory in the absence of collusion and the benefits of the information release for the state seem to be greater for auctions with larger common value components. To be sure, we know of no prosecution of bid rigging in the Oklahoma Department of Transportation (ODOT) auctions during the time period under analysis.

\section{Acknowledgments}

The authors would like to thank George Deltas, Carlos Lamarche, Sanjaya Senadheera, Ken Troske, conference participants at INFORMS 2005 and the 2006 International Industrial Organization Conference, seminar participants at Federal Reserve Bank of Cleveland, Federal Reserve Bank of Philadelphia, Federal Reserve Bank of St. Louis, Concordia University, the University of Minnesota, the University of Oklahoma and Texas Tech University for valuable comments. We are indebted to staff at the ODOT and TXDOT for useful information. The views expressed are those of the authors and do not reflect the views of the Federal Reserve Bank of Cleveland.

\section{Appendix A}

Derivation of the bidding function:

Consider a bidder's expected payoff from participation:

$$
\pi(b)=\left[b-s-\frac{n-1}{n} E_{n-1}\left[v \mid s \geqslant B^{-1}(b)\right]\right]\left[1-F_{s}\left(B^{-1}(b)\right)\right]^{n-1} .
$$

For convenience we suppress the subscript $n-1$ in the expectation. Differentiating the expected payoff with respect to $b$ and evaluating the expression at the optimal choice

\footnotetext{
${ }^{24}$ This recommendation and rationale are discussed in Suggestions for the Detection and Prevention of Construction Bid Rigging (1983) authored by the US Department of Transportation and US Department of Justice (1983) (see http://www.fhwa.dot.gov/programadmin/contracts/dotjbid.htm).
} 
we have

$$
\begin{aligned}
\left.\frac{\partial \pi}{\partial b}\right|_{b=B(x)}= & {\left[1-\frac{n-1}{n}(E[v \mid s \geqslant x]-E[v \mid s=x]) \frac{1}{B^{\prime}(x)} \frac{f_{s}(x)}{1-F_{s}(x)}\right]\left[1-F_{s}(x)\right]^{n-1} } \\
& -\left[B(x)-s-\frac{n-1}{n} E\left[v \mid S^{3} \geqslant x\right]\right](n-1)\left[1-F_{s}(x)\right]^{n-2} f_{s}(x) \frac{1}{B^{\prime}(x)}=0 .
\end{aligned}
$$

Simplifying we get

$$
\begin{aligned}
& {\left[\frac{1}{n-1}-\frac{1}{n}(E[v \mid s \geqslant x]-E[v \mid s=x]) \frac{1}{B^{\prime}(x)} \frac{f_{s}(x)}{1-F_{s}(x)}\right]\left[1-F_{s}(x)\right]} \\
& \quad-\left[B(x)-s-\frac{n-1}{n} E[v \mid s \geqslant x]\right] \frac{f_{s}(x)}{B^{\prime}(x)}=0 \Leftrightarrow \\
& {\left[\frac{1-F_{s}(x)}{f_{s}(x)} \frac{B^{\prime}(x)}{n-1}-\frac{1}{n}(E[v \mid s \geqslant x]-E[v \mid s=x])-B(x)+s+\frac{n-1}{n} E[v \mid s \geqslant x]\right] \frac{f_{s}(x)}{B^{\prime}(x)}=0 \Leftrightarrow} \\
& {\left[\frac{1-F_{y_{1}}(x)}{f_{y_{1}}(x)} B^{\prime}(x)+\frac{1}{n}\left(E[v \mid s=x]+\frac{n-2}{n} E[v \mid s \geqslant x]\right)-B(x)+s\right] \frac{f_{s}(x)}{B^{\prime}(x)}=0 .}
\end{aligned}
$$

We can now show that the following function is indeed the symmetric equilibrium bidding strategy for bidder $i$ in the first price auction:

$$
B(x)=\frac{n-1}{n} E[v \mid s \geqslant x]+E\left[y_{1} \mid y_{1} \geqslant x\right] .
$$

Using the fact that

$$
E[v \mid X \geqslant x]=\int_{x}^{x_{H}} E[v \mid x=w] \frac{f_{x}(w)}{\left(1-F_{x}(x)\right)} \mathrm{d} w
$$

and differentiating (A2) we get

$$
B^{\prime}(x)=\frac{n-1}{n}(E[v \mid s \geqslant x]-E[v \mid s=x]) \frac{f_{s}(x)}{1-F_{s}(x)}+\left[E\left[y_{1} \mid y_{1} \geqslant x\right]-x\right] \frac{f_{y_{1}}(x)}{1-F_{y_{1}}(x)} .
$$

Replacing (A2) and (A3) into (A1) we get

$$
\begin{aligned}
& \frac{1}{n}(E(v \mid s \geqslant x)-E(v \mid s=x))+\left(E\left(y_{1} \mid y_{1} \geqslant x\right)-x\right) \\
& \quad+\frac{1}{n} E(v \mid s=x)+\frac{n-2}{n} E(v \mid s \geqslant x) \\
& \left.\quad-\frac{n-1}{n} E(v \mid s \geqslant x)-E\left(y_{1} \mid y_{1} \geqslant x\right)+s\right] \frac{f_{s}(x)}{B^{\prime}(x)}=0 \\
& {[s-x] \frac{f_{s}(x)}{B^{\prime}(x)}=0 \Rightarrow s=x .}
\end{aligned}
$$

Together with the monotonicity of $B$, this shows that $B\left(s_{i}\right)$ is the bidder's unique optimal bid, i.e.,

$$
B\left(s_{i}\right)=\frac{n-1}{n} E\left[v \mid s \geqslant s_{i}\right]+E\left[y_{1} \mid y_{1} \geqslant s_{i}\right] .
$$




\title{
Appendix B. Supplementary Tables
}

\author{
See Tables B1 and B2
}

Table B1

Regression variables

Independent variable

Description and construction of the independent variable

Relative bid

Relative winning bid

Auctions-specific standard

deviation of relative bids

Auctions-specific range of relative

bids

Oklahoma bids

Bids from November 1999 to

March 2000

Oklahoma bids from November

1999 to March 2000

Bids after March 2000

Oklahoma bids after March 2000

Repeated auctions in Oklahoma

Repeated auctions in Oklahoma from November 1999 to March 2000

Repeated auctions in Oklahoma after March 2000

Number of bidders

Expected number of bidders

Number of plan holders

Capacity utilized

Distance to the project location
Bid divided by the ECE.

Winning bid divided by the ECE.

The standard deviation of relative bids for a given auction.

The auctions-specific range is calculated as the maximum relative bid minus the lowest relative bid.

A dummy variable that identifies the bids in the state of Oklahoma.

A dummy variable that identifies the period between November 1999 and March 2000.

A dummy variable that identifies the bids in the state of Oklahoma between November 1999 and March 2000.

A dummy variable that identifies the period after March 2000.

A dummy variable that identifies the bids in the state of Oklahoma after March 2000.

A dummy variable that identifies the repeated auctions in the state of Oklahoma.

A dummy variable that identifies the repeated auctions in the state of Oklahoma between November 1999 and March 2000.

A dummy variable that identifies the repeated auctions in the state of Oklahoma after March 2000.

The number of bidders in an auction.

The expected number of bidders is calculated using past information for each bidder and the plan holder list. For each bidder at time $t$, we take the past bidding to plan holder ratio. This gives a probability of bidding for each bidder. Then for an auction at time $t$, we sum across these participation probabilities for all plan holders in an auction.

Number of plan holders in an auction.

The utilization rate is the current project backlog of a firm divided by the maximum backlog of that firm during the sample period. For firms that have never won a contract, the utilization rate is set to zero. Data from the year 1997 are used to construct a set of initial starting value for the capacity utilization variable. The 1997 data are not used in the empirical models. The backlog variable is constructed as follows. For each project awarded, both the value of the contract and the length of the contract in days are given. We assume that a project is completed in a uniform fashion over the length of the contract. A contract backlog is constructed in each month by summing across the remaining value of all existing contracts in Texas and/or Oklahoma for a firm. So for both Texas and Oklahoma firms, the backlog includes all awarded projects in the states. As projects are completed, the backlog of a firm goes to zero unless new contracts are won.

The logarithm of the distance to a project is constructed as the distance between the county the project is located in and the distance to the county of the firm's location $[\log ($ distance +1$)]$. The county location is 
Table B1 (continued)

Independent variable Description and construction of the independent variable

Average rivals winning to plan holder ratio

Closest rival's distance to the project location

Rivals minimum backlog

Seasonally unadjusted unemployment rate Three month average of the real volume of projects

Three month average of the number of building permits

Future average real value of projects

Future number of projects

Project-type dummies

Monthly dummies

Project location dummies measured by the longitude and latitude at the centroid of the 'county seat.'

The measure of rivals' past average success $(A R W P)$ in auctions is constructed as the average across rivals of the ratio of past wins to the past number of plans held. This variable incorporates two aspects of past rival bidding behavior. It incorporates both the probability of a rival bidding given they are a plan holder and the probability the rival wins an auction given that they bid. These probabilities are updated monthly using the complete set of bidding data in Texas and Oklahoma. The probabilities are initialized using data from 1997.

This variable measures the distance (log of miles) between the project location and the closest rival.

This variable contains the minimum the backlog of the rival firms in an auction $[\log ($ backlog +1$)]$. See the capacity utilization discussion above for a detailed explanation of how the backlog variable is constructed. The monthly state-level unemployment rate in Oklahoma and Texas from the US Bureau of Labor Statistics.

This variable measures the 3-month moving average of the real volume of all projects for Oklahoma and Texas. The real volume of projects is constructed by adding the ECE across projects up for bid in a month for Oklahoma and Texas, respectively, and deflating the current value by the PPI. Then we divide it by the average of the real volume for each state to calculate the relative real volume.

This variable measures the 3-month moving average of the relative number of building permits for Oklahoma and Texas. The data come from the US Bureau of Economic Analysis.

This variable measures the average relative value of projects per month over the next 3 months.

This variable measures the average relative number of projects over the next 3 months.

All projects are grouped into six main categories based on the description of the project. They are asphalt paving projects, clearance and bank protection projects, bridge projects, grading and draining projects, concrete work and traffic signals and lighting projects. The dummy on asphalt projects is the omitted group in the regressions.

Monthly dummies are set of 12 variables that control for the months of the year. The omitted month is January.

ODOT has divided the state of OK into eight divisions. Similarly TXDOT has divided TX into 25 divisions. OK borders seven of these TX divisions. The project location dummies identify the 15 divisions from which we draw data for our analysis. OK division 1 is the omitted group in the Poisson regressions.

Table B2

Summary statistics of the regression variables

\begin{tabular}{lll}
\hline Variable & Mean & Standard deviation \\
\hline Relative value of bids & 1.068 & $(.288)$ \\
Relative value of winning bids & .949 & $(.194)$ \\
Auctions-specific standard deviation of relative bids & .133 & $(.130)$
\end{tabular}


Table B2 (continued)

\begin{tabular}{lll}
\hline Variable & Mean & Standard deviation \\
\hline Auctions-specific range of relative bids & .326 & $(.308)$ \\
Oklahoma bids & .501 & $(.500)$ \\
Bids from November 1999 to March 2000 & .073 & $(.260)$ \\
Oklahoma bids from November 1999 to March 2000 & .034 & $(.182)$ \\
Bids after March 2000 & .620 & $(.485)$ \\
Oklahoma bids after March 2000 & .308 & $(.462)$ \\
Repeated auctions & .029 & $(.168)$ \\
Repeated auctions in Oklahoma from November 1999 to & .006 & $(.078)$ \\
March 2000 & & \\
Repeated auctions in Oklahoma after March 2000 & .012 & $(.108)$ \\
Number of bidders & 4.697 & $(2.171)$ \\
Expected number of bidders & 4.525 & $(2.203)$ \\
Number of plan holders & 7.627 & $(3.747)$ \\
Capacity utilized & .238 & $(.272)$ \\
Distance to the project location & 4.207 & $(1.581)$ \\
Average rivals winning to plan holder ratio & .149 & $(.054)$ \\
Closest rival's distance to the project location & 2.871 & $(1.725)$ \\
Rivals minimum backlog & 2.380 & $(5.146)$ \\
Seasonally unadjusted unemployment rate & 4.621 & $(1.088)$ \\
Three month average of the real volume of projects & 1.065 & $(.362)$ \\
Three month average of the number of building permits & 1.019 & $(.157)$ \\
Future average real value of projects & 1.078 & $(.361)$ \\
Future number of projects & .995 & $(.271)$ \\
Asphalt projects & .298 & $(.456)$ \\
Erosion control projects & .009 & $(.094)$ \\
Bridge projects & .355 & $(.478)$ \\
Grading and drainage projects & .149 & $(.356)$ \\
Concrete projects & .044 & $(.204)$ \\
Traffic projects & .145 & $(.352)$ \\
\hline
\end{tabular}

\section{References}

Albers, W., Harstad, R.M., 1991. Common-value auctions with independent information: A framing effect observed in a market game. In: Selten, R. (Ed.), Game Equilibrium Models II: Methods, Morals, and Markets. Springer, Berlin, pp. 308-336.

Athey, S., Levin, J., 2001. Information and competition in US Forest Service Timber Auctions. Journal of Political Economy 109 (2), 375-417.

Bajari, P., Ye, L., 2003. Deciding between competition and collusion. Review of Economics and Statistics 85 (4), 971-989.

Bertrand, M., Duflo, E., Mullainathan, S., 2004. How much should we trust differences-in-differences estimates? Quarterly Journal of Economics 119 (1), 249-275.

Bikhchandani, S., Riley, J.G., 1991. Equilibria in open common value auctions. Journal of Economic Theory 53 (1), 101-130.

Bordley, R., Harstad, R., 1996. Lottery qualification auctions. In: Baye, M. (Ed.), Advances in Applied Microeconomics, vol. 6. Auctions, AI Press, Inc.

Bulow, J., Klemperer, P., 2002. Prices and the winner's curse. RAND Journal of Economics 33 (1), 1-21.

Bulow, J., Ming, H., Klemperer, P., 1999. Toeholds and takeovers. Journal of Political Economy 107 (3), 427-454.

Campbell, C.M., Levin, D., 2000. Can the seller benefit from an insider in common value auctions? Journal of Economic Theory 91 (1), 106-120.

De Silva, D.G., Dunne, T., Kosmopoulou, G., 2003. An empirical analysis of entrant and incumbent bidding in road construction auctions. Journal of Industrial Economics 51 (3), 295-316. 
De Silva, D.G., Jeitschko, T.D., Kosmopoulou, G., 2005. Stochastic synergies in sequential auctions. International Journal of Industrial Organization 23 (3-4), 183-201.

Eklof, M., Lunander, A., 2003. Open outcry auctions with secret reserve prices: An empirical application to executive auctions of tenant owner's apartments in Sweden. Journal of Econometrics 114 (2), 243-260.

Goeree, J.K., Offerman, T., 2002. Efficiency in auctions with private and common values: An experimental study. American Economic Review 92 (3), 625-643.

Goeree, J.K., Offerman, T., 2003. Competitive bidding in auctions with private and common values. Economic Journal 113 (489), 598-613.

Harstad, R.M., 1990. Alternative common-value auction procedures: Revenue comparisons with free entry. Journal of Political Economy 98 (2), 421-429.

Hendricks, K., Porter, R.H., 1988. An empirical study of an auction with asymmetric information. American Economic Review 78 (5), 865-883.

Hendricks, K., Porter, R.H., Boudreau, B., 1987. Information, returns, and bidding behavior in OCS auctions1954-1969. Journal of Industrial Economics 35 (4), 517-542.

Hendricks, K., Porter, R.H., Wilson, C.A., 1994. Auctions for oil and gas leases with an informed bidder and a random reservation price. Econometrica 62 (6), 1415-1444.

Hendricks, K., Pinkse, J., Porter, R.H., 2003. Empirical implications of equilibrium bidding in first-price, symmetric, common value auctions. Review of Economic Studies 70 (1), 115-145.

Hong, H., Shum, M., 2002. Increasing competition and the winner's curse: Evidence form procurement. Review of Economic Studies 69, 871-898.

Jofre-Bonet, M., Pesendorfer, M., 2003. Estimation of a dynamic auction game. Econometrica 71 (5), 1443-1489.

Kagel, J.H., Levin, D., 1986. The winner's curse and public information in common value auctions. American Economic Review 76 (5), 894-920.

Kagel, J.H., Harstad, R.M., Levin, D., 1987. Information impact and allocation rules in auctions with affiliated private values: A laboratory study. Econometrica 55 (6), 1275-1304.

Kagel, J.H., Levin, D., Harstad, R.M., 1995. Comparative static effects of number of bidders and public information on behavior in second-price common value auctions. International Journal of Game Theory 24 (3), 293-319.

Klemperer, P., 1998. Auctions with almost common values: The 'Wallet Game' and its applications. European Economic Review 42 (3-5), 757-769.

Koenker, R., Bassett Jr., G., 1982. Robust tests for heteroscedasticity based on regression quantiles. Econometrica 50 (1), 43-61.

Krishna, V., 2002. Auction Theory. Academic Press, San Diego, CA.

Krishna, V., Morgan, J., 1997. (Anti-) Competitive Effects of Joint Bidding and Bidder Restrictions," (Mimeo Penn State).

Levin, D., Smith, J.L., 1994. Equilibrium in auctions with entry. American Economic Review 84 (3), 585-599.

Mares, V., Harstad, R.M., 2003. Private information revelation in common value auctions. Journal of Economic Theory 109 (2), 264-282.

Milgrom, P.R., 2004. Putting Auction Theory to Work. Cambridge University Press, New York, NY.

Milgrom, P.R., Weber, R.J., 1982. A theory of auctions and competitive bidding. Econometrica 50 (5), 1089-1122.

Moulton, B.R., 1990. An illustration of a pitfall in estimating the effects of aggregate variables on micro units. Review of Economics and Statistics 72 (2), 334-338.

Nyborg, K.G., Kristian, R., Sundaresan, S.M., 2002. Bidder behavior in multiunti auctions: Evidence from Swedish treasury auctions. Journal of Political Economy 110 (2), 394-424.

Porter, R.H., 1995. The role of information in US offshore oil and gas lease auction. Econometrica 63 (1), 1-27.

Porter, R.H., Zona, J.D., 1993. Detection of bid rigging in procurement auctions. Journal of Political Economy 101 (3), 518-538.

US Department of Transportation; US Department of Justice, 1983. Suggestions for the Detection and Prevention of Construction BidRigging," 〈http://www.fhwa.dot.gov/programadmin/contracts/dotjbid.htm $\rangle$.

Vincent, D.R., 1995. Bidding off the wall: Why reserve prices may be kept secret. Journal of Economic Theory 65 (2), 575-584.

Wilson, R., 1969. Competitive bidding with desperate information. Management Science 15, 446-448.

Yin, P.-L., 2006. Information dispersion and auction prices. Harvard Business School Working Paper, No. 06-010. 